\title{
ONLINE HOTEL RESERVATION AND MANAGEMENT SYSTEM FOR THE COLLEGE OF INTERNATIONAL TOURISM AND HOSPITALITY MANAGEMENT (CITHM)
}

\author{
Glenda A. Delizo, Mischelle A. Esguerra \\ Instructor, College of Computer Studies, \\ Lyceum of the Philippines University, Batangas City, Philippines \\ glenda.delizo@gmail.com \\ Instructor, College of Computer Studies, \\ Lyceum of the Philippines University, Batangas City, Philippines \\ mischel_32@yahoo.com
}

\begin{abstract}
This study aims to develop and design an on-line hotel reservation and management system for the College of International Tourism and Hospitality Management of the Lyceum of the Philippines University, Batangas Campus. It presents user-friendly features that will familiarize CITHM students on the online hotel reservation system, evaluate it and highlight the benefits it can provide to the college and staff. In addition, it will purvey supplement material in their front desk operation course. The researchers used the System Development Life Cycle and Microsoft Web Developer 2008 as the programming language. The developed software served as a tool for the students of CITHM to familiarize them on how to operate an online hotel reservation system. The developed software was an effective aid for the instructors in teaching the basic operations of hotel reservation system to their students. It also provided online security to protect privacy and financial information of clients.
\end{abstract}

\section{Indexing terms/Keywords}

Online systems, hotel reservation system, hotel management system.

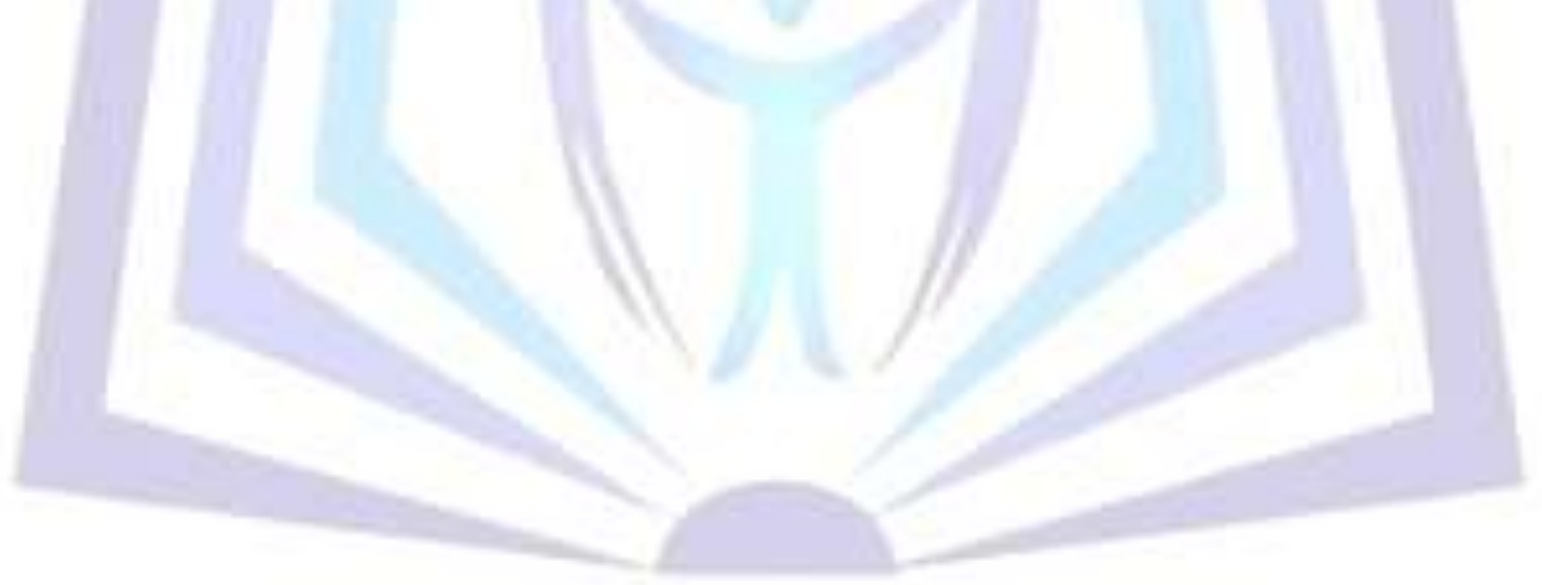

\section{Council for Innovative Research}

Peer Review Research Publishing System

Journal: INTERNATIONAL JOURNAL OF COMPUTERS \& TECHNOLOGY

\author{
Vol 10, No 1 \\ editor@cirworld.com \\ www.cirworld.com, member.cirworld.com
}




\section{INTRODUCTION}

The Lyceum of the Philippines University with its continuing aim of providing quality education through excellent instruction and giving better facilities and resources had never stopped giving quality standards that the students should have to be able to compete locally and internationally.

The College of International Hospitality Management (CITHM) of this institution, one of the province's pioneer in providing future hoteliers and restaurateurs, aims to continuously produce topnotch graduates. The college also imbibes in the students the basic principles and knowledge that will help them in the analysis and understanding of the complexities of hotel and restaurant business, to produce skilled and knowledgeable chef, food supervisors, hotel managers, reservation clerks, front desk managers, sales representatives of hotel and other related works.

One of the most important skills that HRM students should have is the knowledge of using an on-line hotel reservation system. Hotel reservation system has been designed to simplify the task of on-line booking and to enable hotel businesses to compete in today's demanding and competitive market. The system provides the customers and clients a unique, innovative and easy to use interface that improves the way people use the web today. Online users can compare prices and facilities at different hotels.

Online hotel reservations systems are becoming a very popular method for booking hotel rooms. Travelers can book rooms from home by using an online security to protect their privacy and financial information.

The researchers believe that the knowledge gained in the development of the system will be an effective tool in providing the needed IT skills of the students in the industries. It will be beneficial to the University since the use of the system as a teaching tool will improve the delivery of instruction and prove to be cost-efficient.

\section{OBJECTIVES OF THE STUDY}

This study aims to develop an on-line hotel reservation system for the College of International Tourism and Hospitality Management. Specifically, this study has the following objectives:

1. To design an online hotel reservation system for the College of International Hospitality Management.

2. To providefeatures that will familiarize CITHM students with the online hotel reservation system.

3. To evaluate the system and highlight the benefits the system can provide to the college and staff.

\section{LITERATURE REVIEW}

The application of the Internet in the business world has become a major trend in practice and generated a hot stream of research in the recent literature. The Internet, as a collection of interconnected computer networks, provides free exchanging of information. Over 400 millions of computers or more than 400,000 networks worldwide today are communicating with each other (Napier, Judd, Rivers, and Wagner, 2001). As such, the Internet has been becoming a powerful channel for business marketing and communication (Palmer, 1999), and for new business opportunities - as it is often called as "e-business" or "e-commerce" today (Schneider \& Perry, 2001). This new e-business or e-commercevirtual marketplace allows small companies competing with business giants by just having a better web presentation of their products/services. Under the same wave, online customers can enjoy a wider choice of products or services, more competitive prices, and being able to buy their favorite items/services from the sellers located thousands miles away. It provides communication between consumers and companies and throughelectronic data interchange (EDI), buyers and sellers can exchange standard business transactions such as invoices or purchase orders with remarkable ease.

The hotel industry is certainly full aware of this trend and fully willing to contribute its share in this effort. In fact, the industry has realized that during those early forays into cyberspace, the industry didn't view e-booking strategically (many hotels simply considered online room bookings at the time as a way to pick up additional business by selling distressed inventory through those online travel agencies), and handed over too much control of inventory and pricing to those third party online travel agencies.Now the industry is in the unenviable position of trying to take back the reins after early shopping patterns have been established. While the pressure to sell their inventory rooms online will be continuing, the industry has developed its new online strategy striving to get a better grip on this emerging marketing channel. (http://www.iima.org/CIIMA/CIIMA\%20V3\%20N1\%201\%20Yang.pdf)

Online system has evolved to be a cornerstone in support of computer software users of all kinds. It is an electronic interactive system that delivers information to users via telephone lines to personal computers (PCs) or via cables to terminals. Such a service provides information, usually in text form, about news, education, business, entertainment, shopping, and more. Some also provide message services and graphic and audio information. (http://www.britannica.com/EBchecked/topic/429262/online-system)

Online hotel reservations are becoming a very popular method for booking hotel rooms. Travelers can book rooms from home by using online security to protect their privacy and financial information and by using several online travel agents to compare prices and facilities at different hotels. People can book directly on an individual hotel's website. An increasing number of hotels are building their own websites to allow them to market their hotels directly to consumers. Non-franchise chain hotels require a "booking engine" application to be attached to their website to permit people to book rooms in real time. One advantage of booking with the hotel directly is the use of the hotel's full cancellation policy as well as not needing a deposit in most situations. (http://en.wikipedia.org/wiki/Online hotel reservations) 
Online Hotel Reservation Software (OHRS) is an easy to use arrangement that enables agents and guests to reserve rooms directly via the internet once they have confirmed availability of rooms in accordance with the itinerary.

OHRS is an efficient and brilliant software, yet it is easy and uncomplicated to use. OHRS grants complete authority and power on hotel or motel room booking over the internet. This entails that one can accumulate all guest payments; enter own room descriptions, facilities, rates and allocations into the Reservation System. OHRS also allows to confirm accommodation in real-time at hotel's web site and close the sale without more ado.

\section{(http://www.dotcomtechno.com/ohrm.html)}

There are several benefits of OHRS. It makes the reservation process computerized and thus helps one to undertake a large amount of transactions at a low cost. It lets the hotel in charge of over margins and pricing strategy. It enables one to check available inventory and complete an online booking form making the reservation process more efficient and less time consuming. The clients can settle the room rates and special offers at no extra cost.

OHRS assists hotel's guests and agents with different payment options such as credit/debit cards. The system can track hotel's performance on a regular basis as all information concerning payments is updated online and sent to the reservation manager by means of e-mail or mobile messages.

Gatesix Hospitality offers online hotel reservation system development services for lodging industry including Inns, motels and resorts. Gatesix provides its hotel clients with the highest quality Internet presence as well as a seamless, embedded online reservation engine that allows for easy navigation for the consumer and greater flexibility for the hotelier. Their online hotel reservation system, "gRes" was crafted from strategic knowledge of the hotel business and a passionate commitment to excellence in hospitality services. (http://www.gatesixhospitality.com/online-hotel-reservation-system.php)

BugHotel Reservation System was designed to simplify the task of online booking. It provides users a unique, intuitive and easy to use interface that improves the way people use the web today. Through personalization and rich features, BugHotel Reservation System enhances the entire Web experience. BugHotel Reservation System offers an online web based reservation system for hotels, properties, motels and b\&bs at affordable prices. (www.bughotel.com)

Online hotel reservations are also helpful for making last minute travel arrangements. Hotels may drop the price of a room if some rooms are still available. Large hotel chains typically have direct connections to the airline national distribution systems. These in turn provide hotel information directly to the hundreds of thousands of travel agents that align themselves with one of these systems. Individual hotels and small hotel chains often cannot afford the expense of these direct connections and turn to other companies to provide the connections.

Several large online travel sites are, in effect, travel agencies. These sites send the hotels' information and rates downstream to literally thousands of online travel sites, most of which act as travel agents. They can then receive commission payments from the hotels for any business booked on their websites.

Lastly, people can book directly on an individual hotel's website. An increasing number of hotels are building their own websites to allow them to market their hotels directly to consumers. Non-franchise chain hotels require a "booking engine" application to be attached to their website to permit people to book rooms in real time. One advantage of booking with the hotel directly is the use of the hotel's full cancellation policy as well as not needing a deposit in most situations.

To improve the likelihood of filling rooms, hotels tend to use several of the above systems. The content on many hotel reservation systems is becoming increasingly similar as more hotels sign up to all the sites. Companies thus have to either rely on specially negotiated rates with the hotels and hotel chains or trust in the influence of search engine rankings to draw in customers.

The ultimate service provided by these companies to the hotels and the online consumer is that they provide a single database from which all reservation sources draw immediate room availability and rates. It is very important that hotels integrate with all the supply channels so that their guests are able to make accurate online bookings.

There are many ways of making the online reservation, most of the online reservation systems use the centralized system for making the reservation with the hotel directly. The online hotel reservation through the centralized system is just the tentative reservation, means that a client do not need to pay at the time of reservation and instead pay at the time of check in or check out.

Stuart (1995) in a study entitled "International Reservations Systems - Their Strategic and Operational Implications for the UK Hotel Industry", presented details of the method and results of an investigation of the role and influence of international reservations systems within the UK hotel industry. The research comprised three questionnaire surveys of the use of computer reservations systems and distribution services by UK hotels. These were analysed and produced an indication of general use of systems and the contribution which these currently make to hotel groups and consortia. The work also included a study of developments in access methods and changes in buyer behavior as observed by representatives of computer reservation and distribution system, travel agency, hotel representation and intermediary companies.

The case study made by Jiaqin Yang, Jan Flynn and Krista Anderson of Georgia College and State University (2005) aimed to describe some recent development of e-business application in the hospitality industry ( e.g. travel industry, and recreational entities) and illustrate with two case studies. One is about a local hotel industry's effort to use the Internet to boost its local market. Another describes the operations and its competitive strategy of an emerging online travel agency. The research objective is to investigate the trends and level of prevalence of application of the Internet in the hospitality industry focusing on some emerging issues and challenges. 
Casa Intramuros Reservation System was used by CITHM students as a front desk operation simulation only. It has 9 modules which consist of reservation, registration, checking reservation, room orders, billing system, housekeeping, main panel, reports and user's module. The system provided hands-on training for the students to explore and know the step by step procedure in dealing with hotel reservation system. This system is similar with the system developed by the authors in a way that it provided a hotel reservation and management system.

OPERA System is the MICROS property management system used in many large hotel chains, such as Travelodge Hotels UK, Hyatt Hotels and Resorts, Rydges Hotels and Resorts, Marriott Hotels, Resorts and Suites, Radisson Hotels and Resorts (subsidiary of Carlson Companies), the InterContinental Hotels Group and the Thistle Hotels.Designed to meet the varied requirements of any size hotel or hotel chain, OPERA PMS provides all the tools a hotel staff needs for doing their day-to-day jobs - handling reservations, checking guests in and out, assigning rooms and managing room inventory, accommodating in-house guest needs, and handling accounting and billing.

Opera can essentially be the only management software a hotel needs, as it can handle Reservations, Customer Profiles, Housekeeping Management, Maintenance logs, Cashiering, Accounts Receivable, Agent commissions and third party interfaces such as Minibar systems or Guest TV. Arrivals and in-house guests are served using the Front Desk features of the property management software. This module handles individual guests, groups, and walk-ins, and has features for room blocking, managing guest messages and wakeup calls, and creating and following up on inter-department memos.

\section{METHOD}

\section{- Research Design}

A system is a group of interdependent items that interact regularly to perform a task. A computerized system is developed through a process called System Development Life Cycle (SDLC).

SDLC is a logical process used by a systems analyst to develop an information system, including requirements, validation, training, and user ownership. Any SDLC should result in a high quality system that meets or exceeds customer expectations, reaches completion within time and cost estimates, works effectively and efficiently in the current and planned Information Technology infrastructure, and is inexpensive to maintain and cost effective to enhance. It adheres to important phases that are essential for developers, such as planning, analysis, design, and implementation.

The system will be deployed via the Internet.The researchers used Microsoft Web Developer 2008 as a programming language. Microsoft Visual Web Developer was used to create web sites, web applications and web services using ASP.NET. It is an Integrated Development Environment (IDE) that provides a set of tools and utilities for developing ASP.Net 2.0 web applications. It is a part of Microsoft Visual Studio 2005 that can be used to develop powerful ASP.Net web applications using various tools for developing web applications included in .Net Framework. Visual Web Developer offers the programmer benefits of productivity and easy web site administration utilities along with wide variety of improvements that provide much better IDE. Microsoft Visual Studio 2005 Edition includes many improvements that enable one to create the ASP.Net 2.0 web applications by using pre-built server controls and developing rich user-friendly features with few lines of code.

Since, the system will handle a large volume of data for creating accounts and hotel reservation it required a large storage in a form of database. A database is a repository of interrelated data organized by software called Database Management System (DBMS). For this purpose, the researchers used MySQL Server 2005. MySQL serves as a tool for storing record. It provides quick access to the data with the combination of Visual Web Developer for the proper display of information.

Further, for documentation purposes, the authors used a tool to aid them in the designing phase. Flowcharts were created to help in the visual organization of the content and for finding flaws in the process if there is any.

\section{- Participants}

In the completion of this study, the following people were deemed to play very important roles.

The authors, in particular the developers are responsible for the layout of the entire system and responsible for the coding and testing. The final output is expected to be user-friendly as possible and easy to access and manage as well.

The end-users are the faculty members and students from the College of International Tourism and Hospitality Management. The faculty members teaching Front Desk Operations will be the administrator that will be responsible for adding, editing and deleting user accounts as well as the rooms of the hotel. They will also have the capability to use the extend reservation button for extending the reservation of the clients and cancelled reservation button for cancelling the reservations. The students, on the other hand can view the reservations using the View reservation button. It is like a record keeping tool in order to know when the clients have checked in or when they checked out.

\section{- Data Analysis}

Part of the design phase was the use of the flowchart that served as schematic representation of the program flow. This was an important part of the development process since the processes were visually presented for easy understanding. 


\section{RESULTS}

In the design and development of the "Online Hotel Reservation and Management System for the College of International Hospitality Management (CIHM)", the following flowcharts and screen shots aided the researchers.

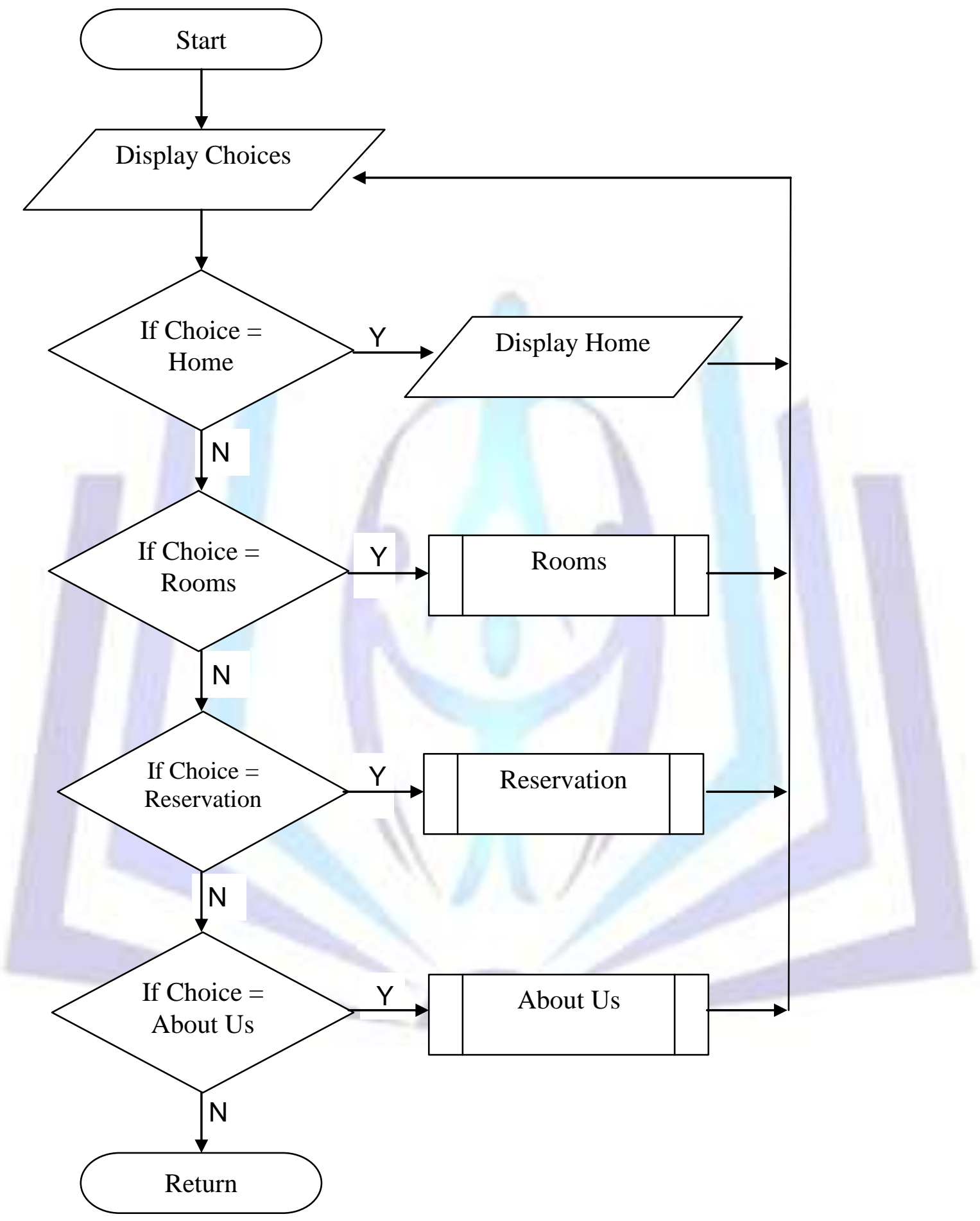

Figure 1. Home

Figure 1 shows the opening page when the users access the Online Hotel Reservation System. It shows the major links that allow the user to select options when the system is accessed. It contains buttons like Home Page, Rooms for viewing the available rooms of the hotel, Reservation when making reservations and About Us which contains information about the developer of the system. 


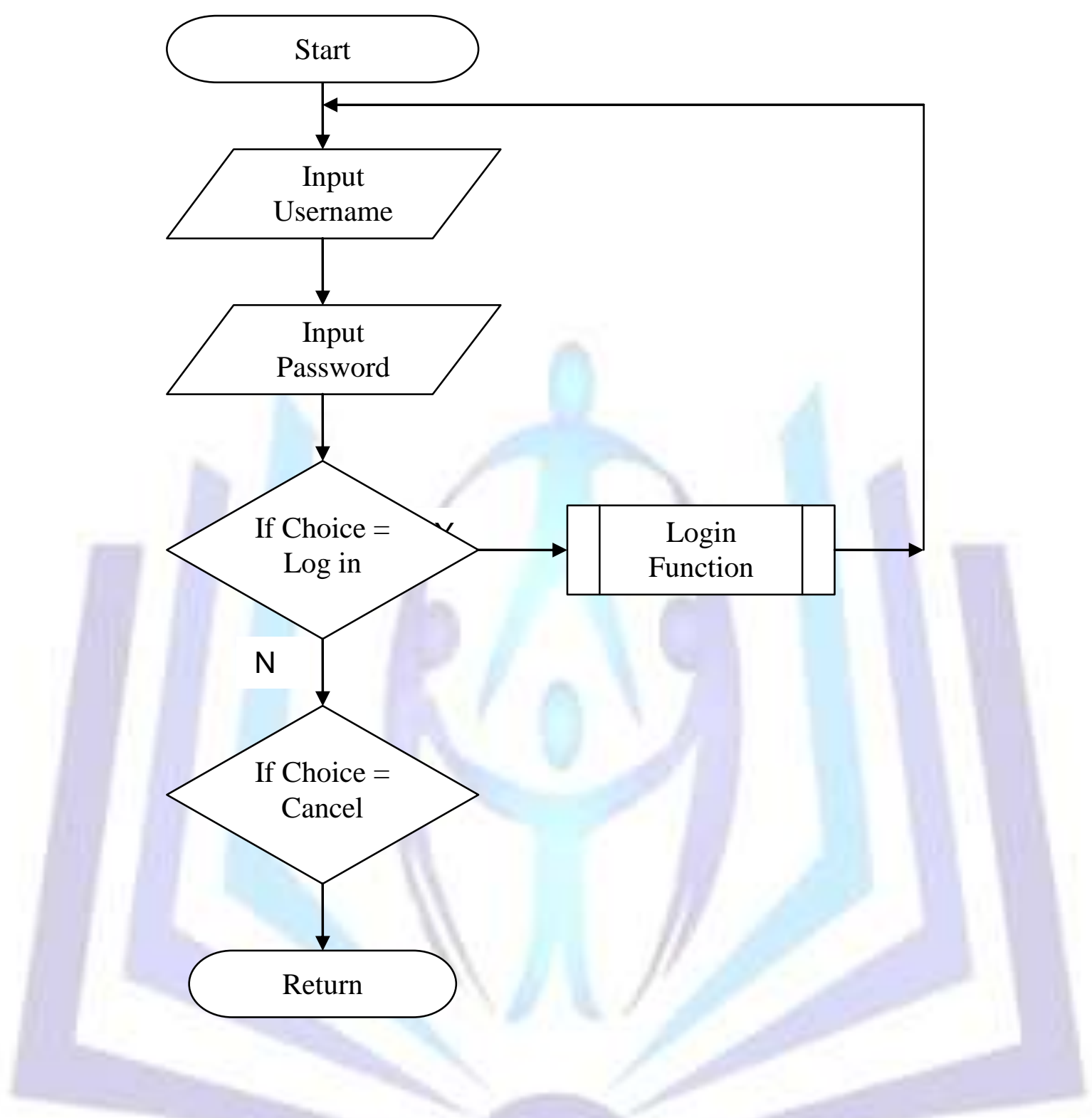

Figure 2. Login

Figure 2 shows the login page wherein the user will input username and password in order to access the database of the system. The user may login as an administrator, a student and as a client. 




Figure 3. Login Function

This figure shows the login function that displays the different types of users who can access the database of the system. Every user type needs a valid username and password. 


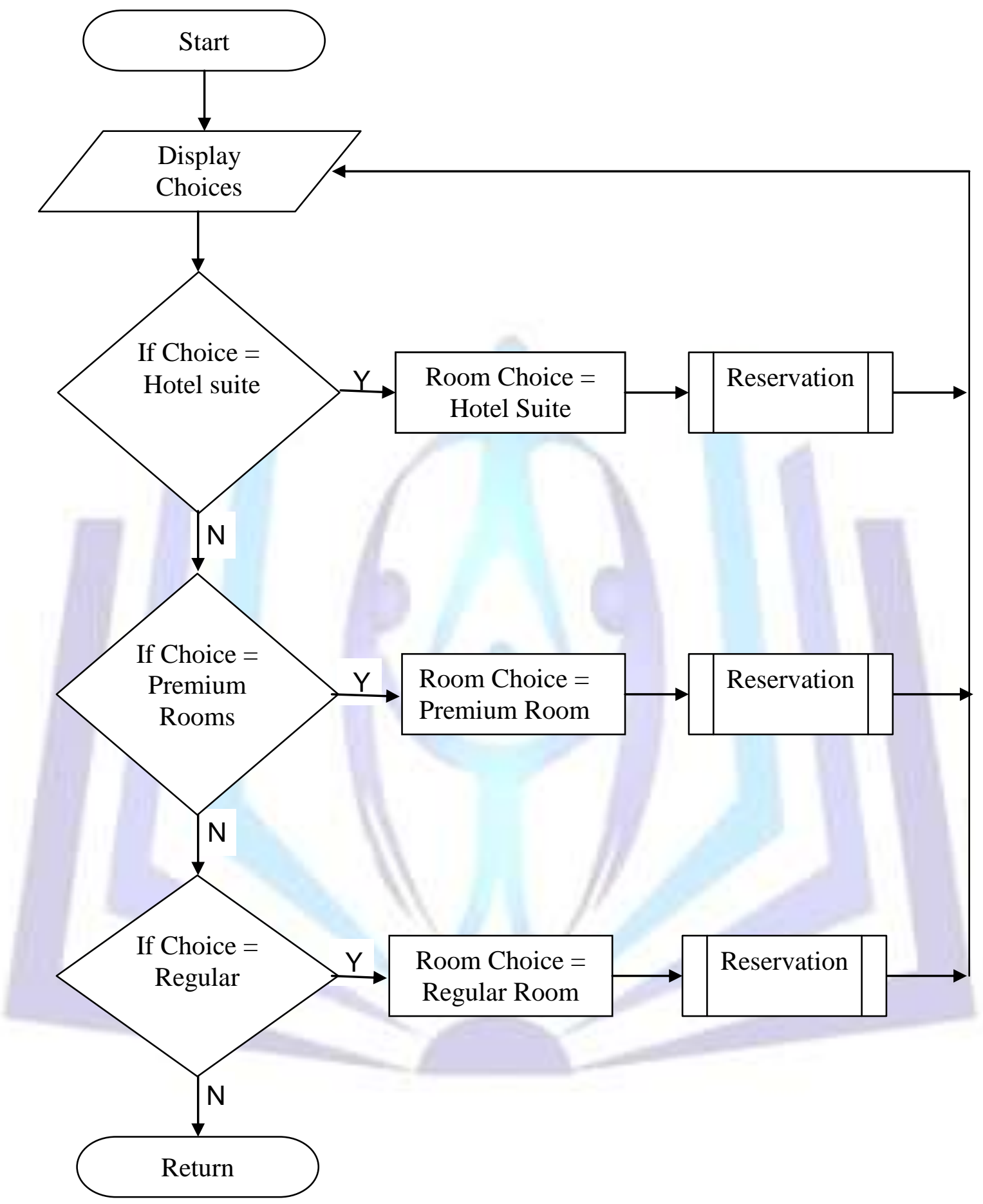

Figure 4. Rooms

Figure 4 shows the sublinks if the Rooms link in the Home page is clicked. It displays the available rooms of the hotel like Hotel Suite, Premium Rooms and Regular Rooms wherein user can choose from. If the user selects each room, it will be redirected to reservation button to make reservation. 


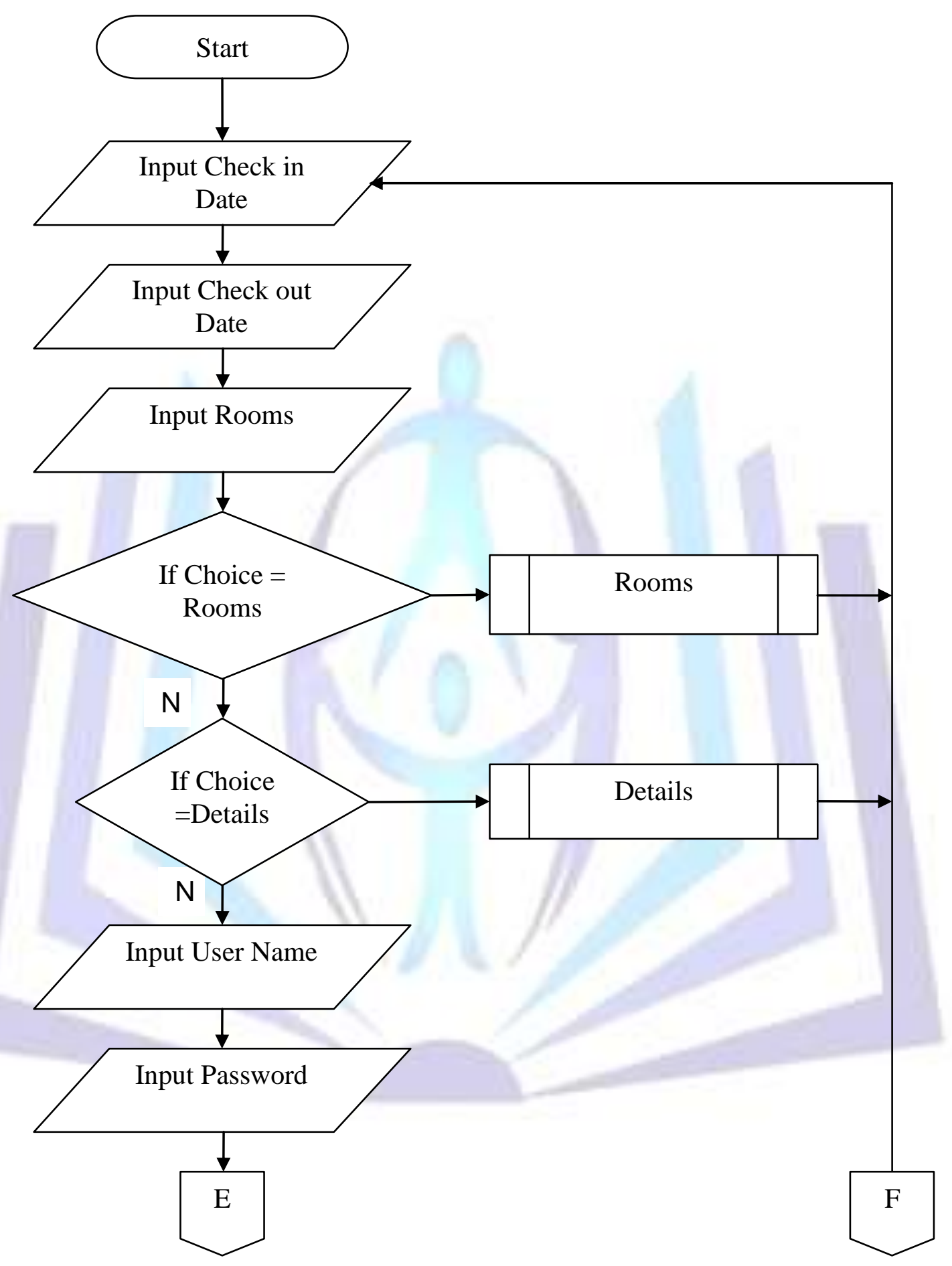

Figure 5. Reservation 

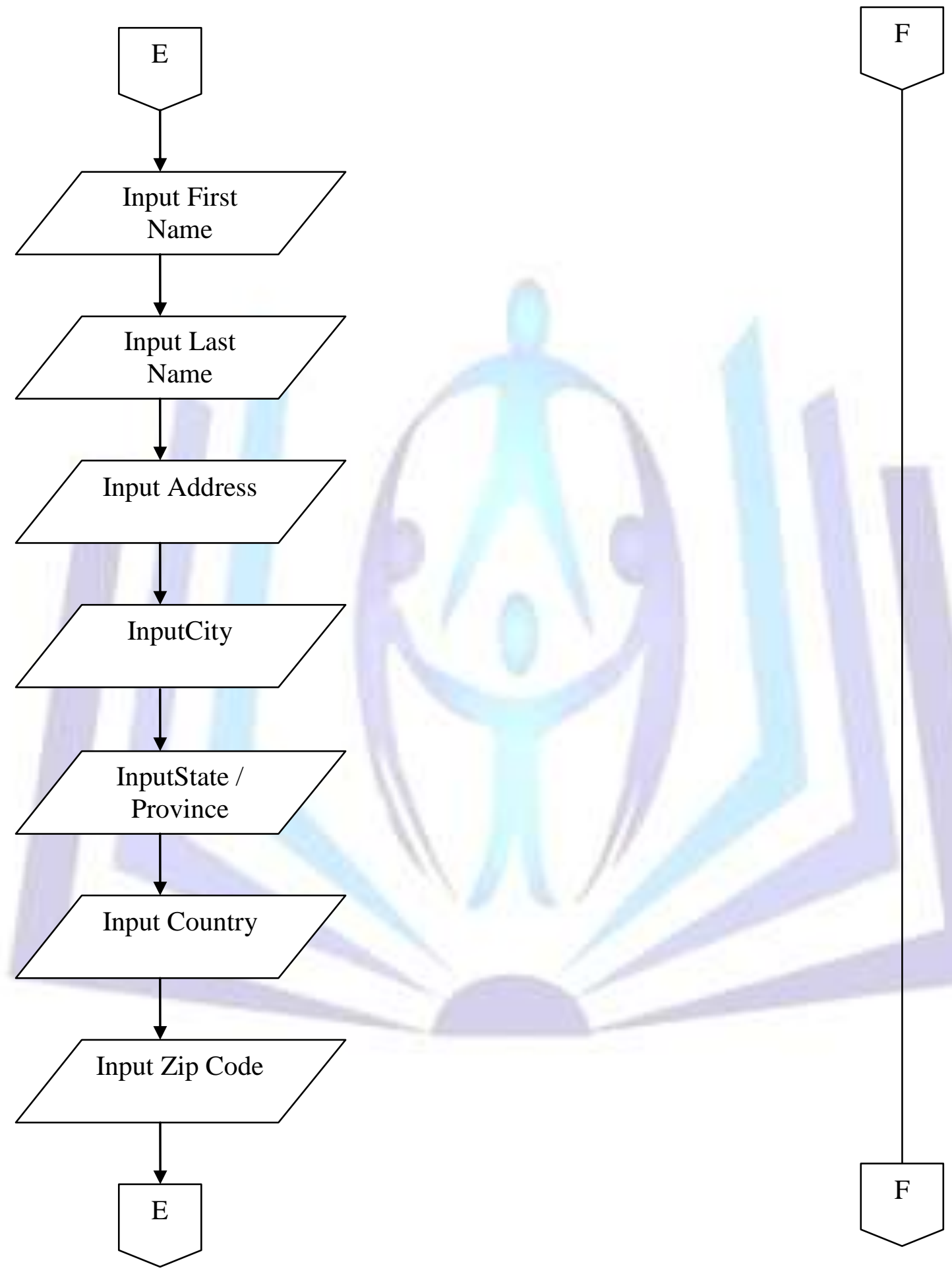

Figure 5.1 Reservation (Continued) 




Figure 5.2 Reservation (Continued)

Figures 5, 5.1 and 5.2 display the process of making reservations when the Reservation button on the main page is clicked. In order to make the reservation, the user need to fill up the necessary information provided to be registered on the system. At first, the user will be asked to input the desired rooms under the Rooms link. At the Detail link the user need to input the username and password and the personal information of the user making the reservation. To confirm the reservation process, the user needs to pay the $10 \%$ down payment through credit cards. 


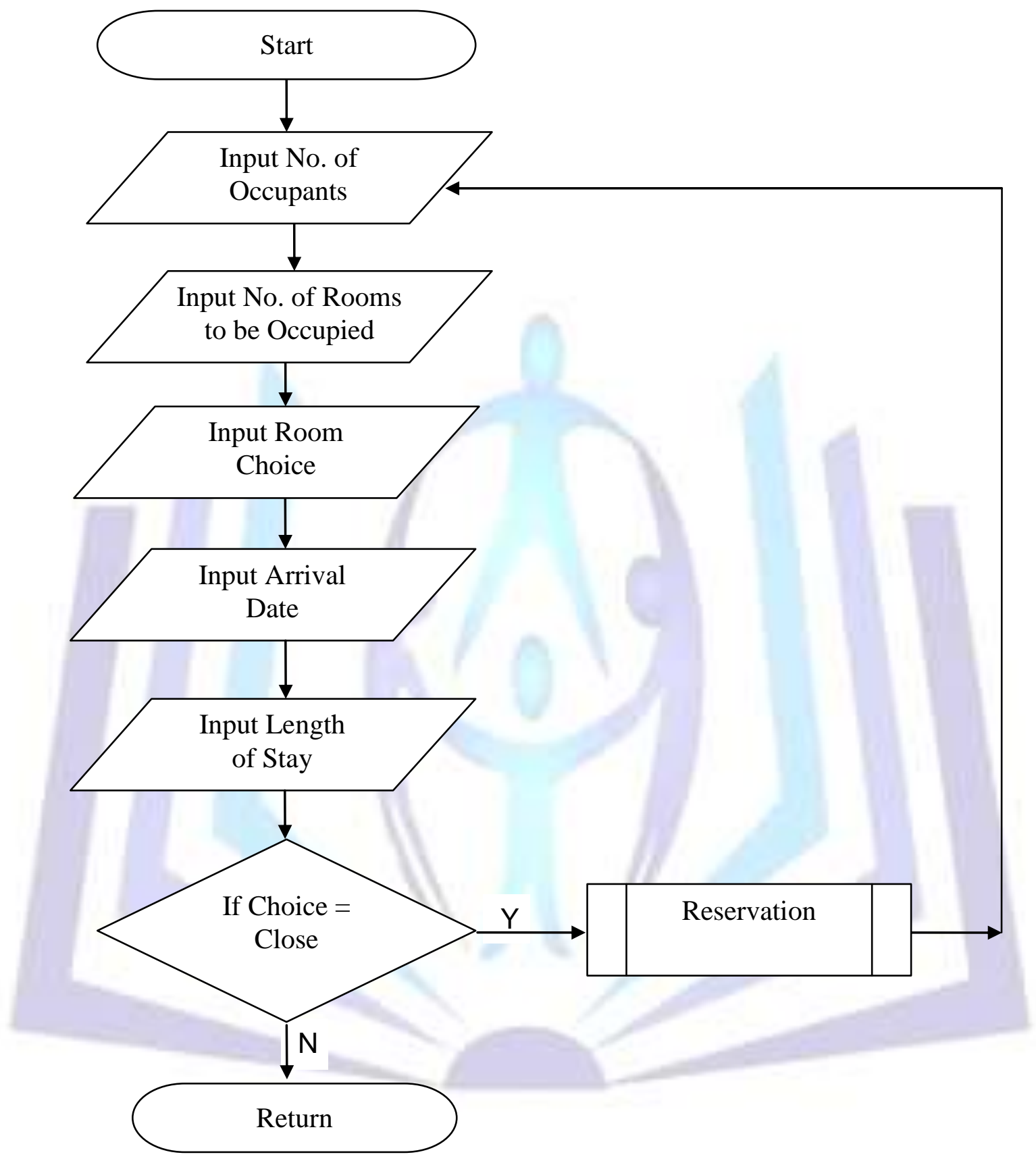

Figure 6. Details

Figure 6 displays the details of the reservation process. With this, the user will specify how many occupants will occupy the room, the type and number of rooms and as well as the length of stay. 




Figure 7. Payment

This figure shows the payment scheme to be made by the user or the customer in order to confirm the reservation. The system will compute first the total reservation fee based on the rate of the hotel room and the length of stay and then get the $10 \%$ of this as down payment. 


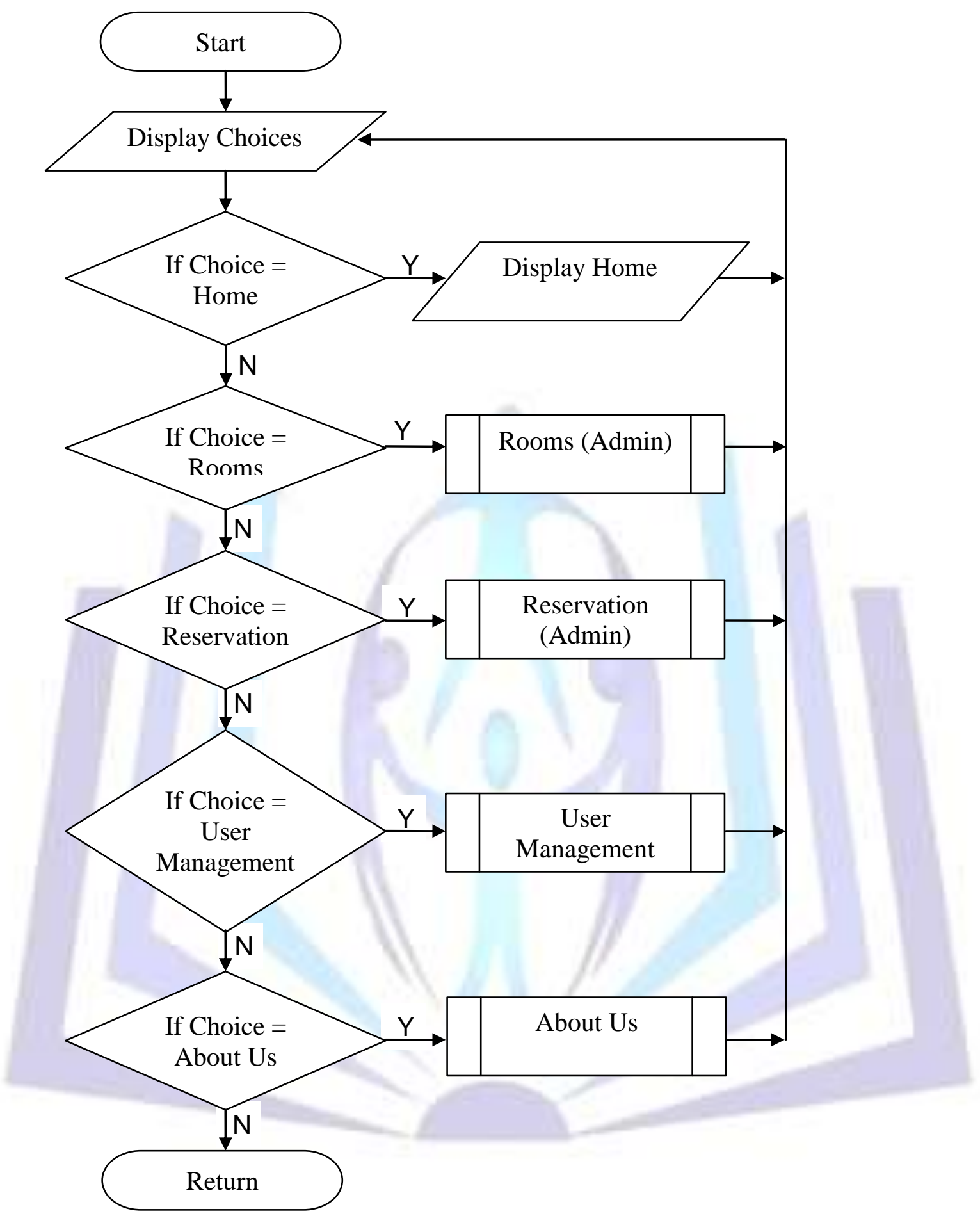

Figure 8. Administrator

Figure 8 displays the account for the Administrator once the user logged in as an administrator. It contains major links- Home, Rooms, Reservation, User Management and About Us. User Management allows the administrator to add, edit and delete accounts of the users who will access the system. 


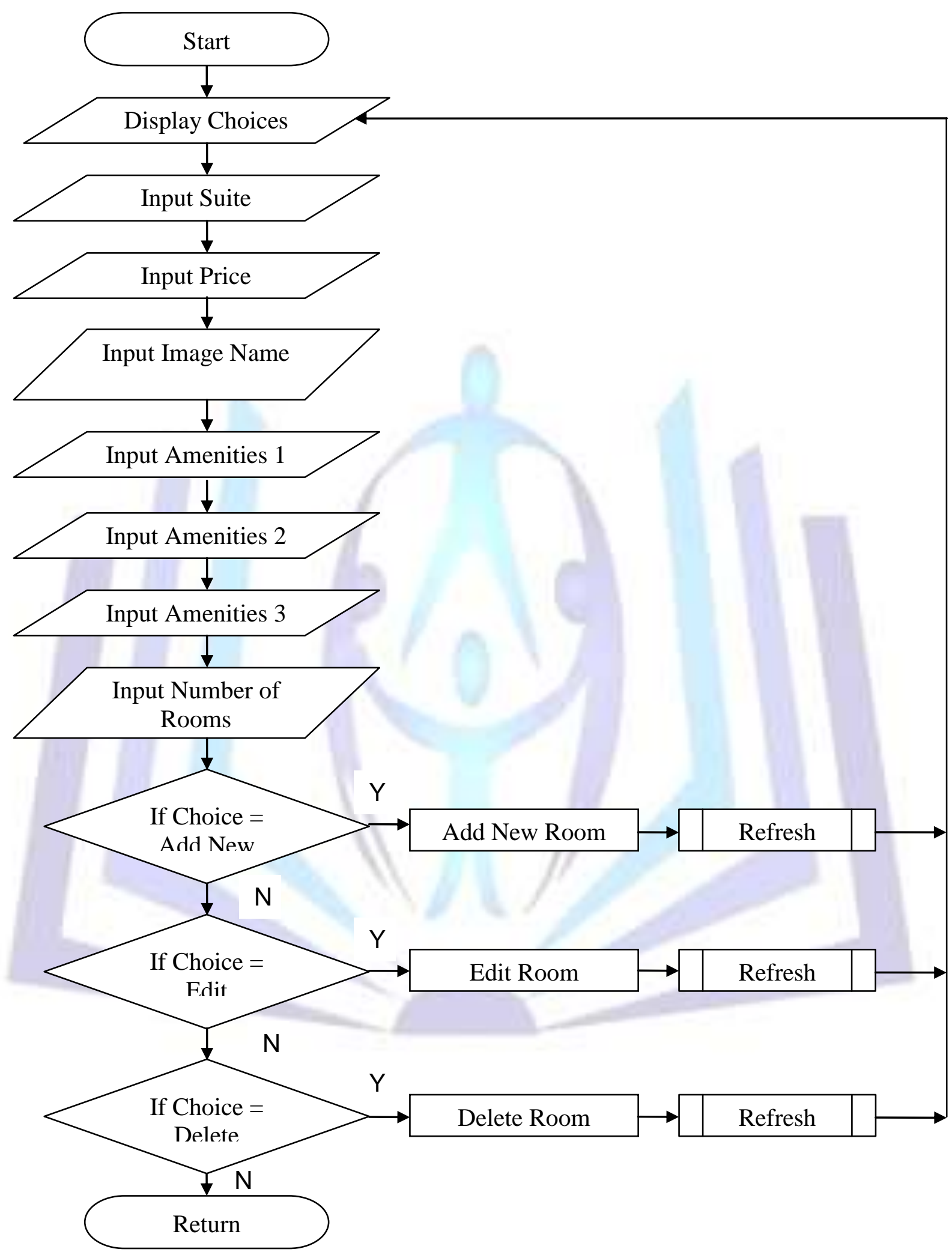

Figure 9. Rooms (Admin)

The figure displays the page when Rooms link under the administrator account is clicked. This will enable the administrator to manipulate the system like inputting suite, price, image and amenities of the hotel. The administrator can also add, edit, and delete rooms of the hotel. 


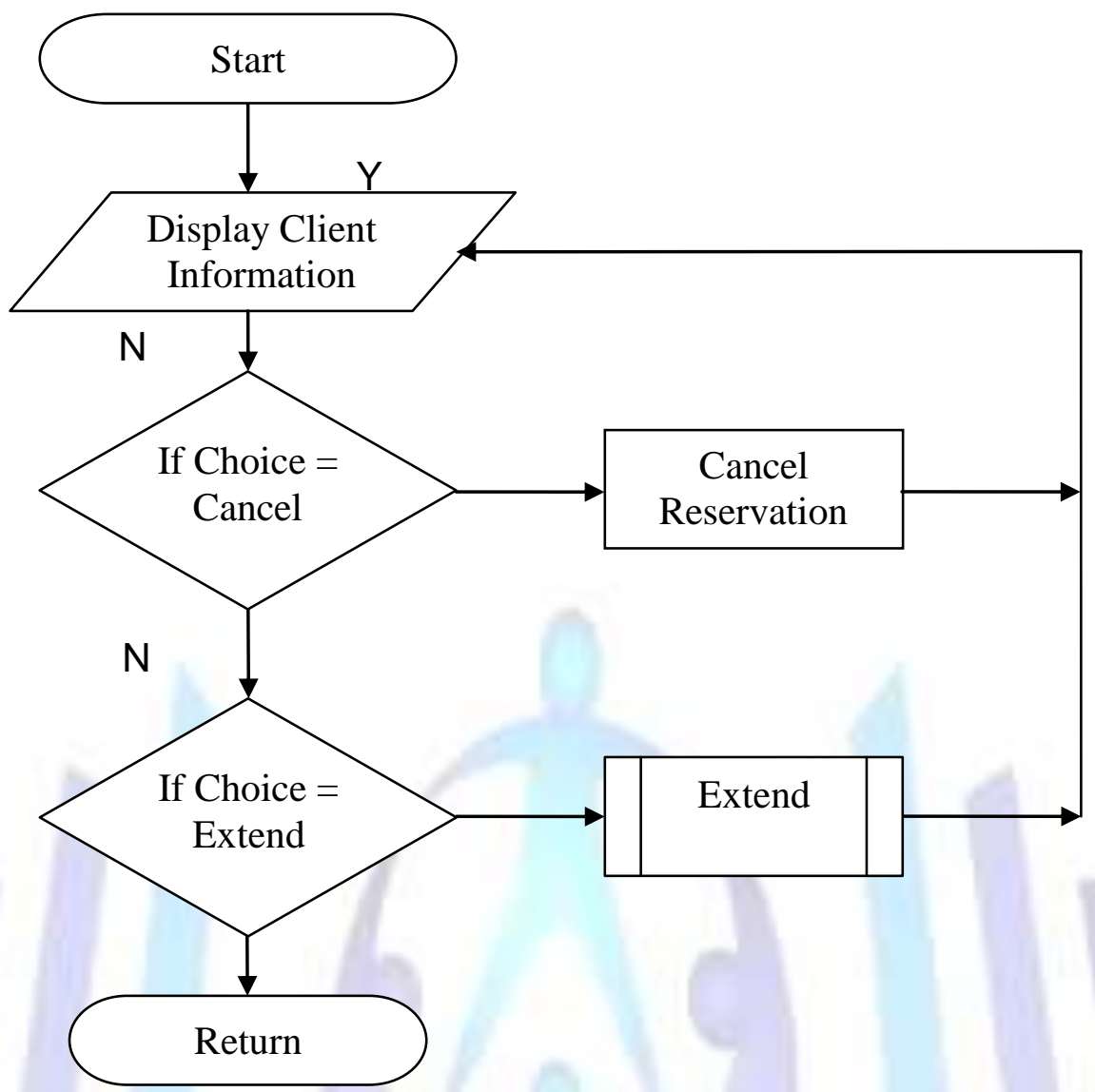

Figure 10. Reservation (Admin)

Figure 10 shows the cancelling and extending the reservation process under the administrator account. This will display the information of the client who registers on the system. The administrator only has the capability to cancel or extend the reservation of the client.

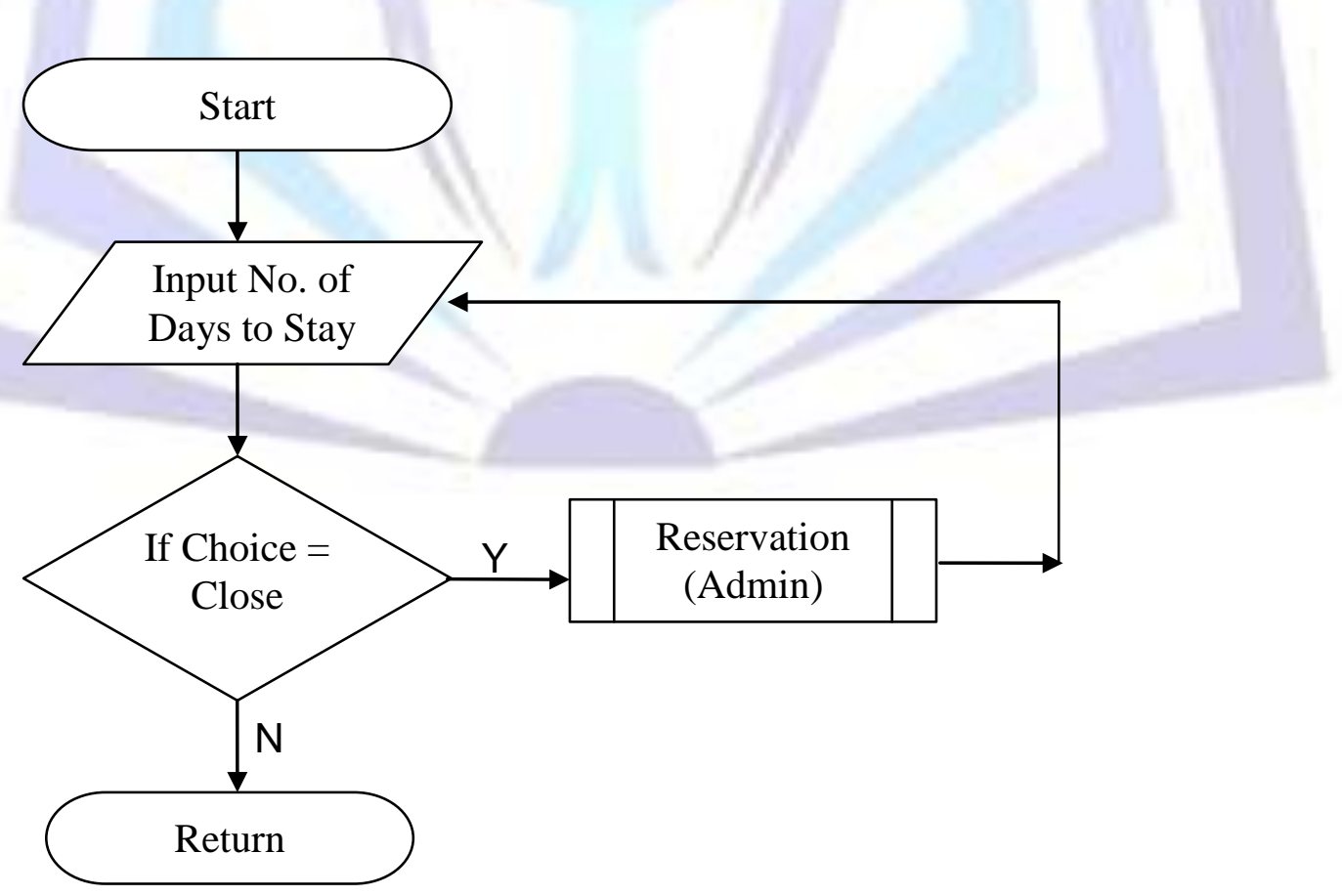

Figure 11. Extend

This figure shows the process of extending the reservation wherein the administrator will update the length of stay of the guest. Afterwards, if the administrator chooses Close, the page will be redirected to the Reservation page. 


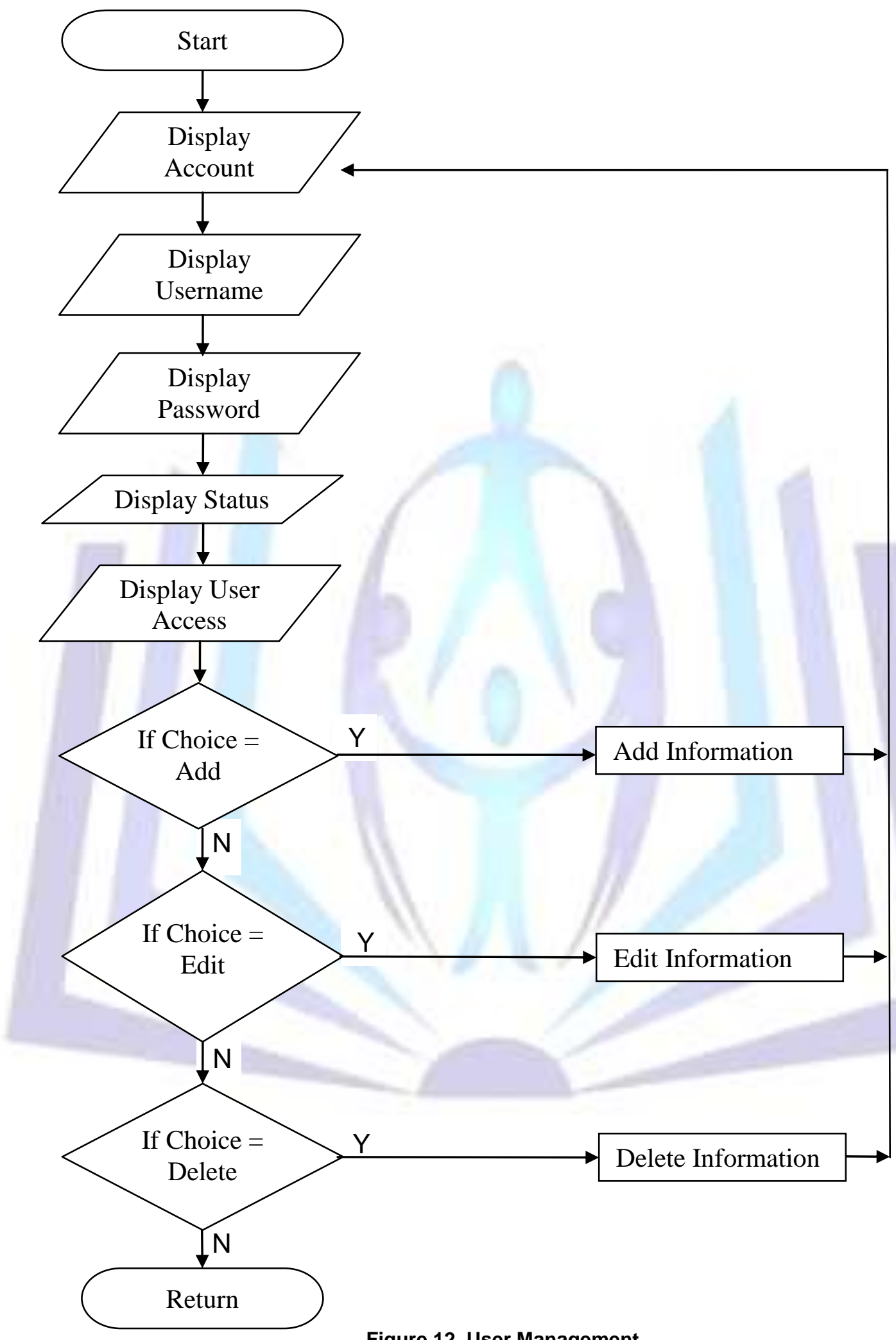

Figure 12. User Management

This figure shows the User Management button for the administrator account. In this button, the administrator can view the username and password of the client who register on the system. The administrator also has the option to add, edit and delete the information of the client. 


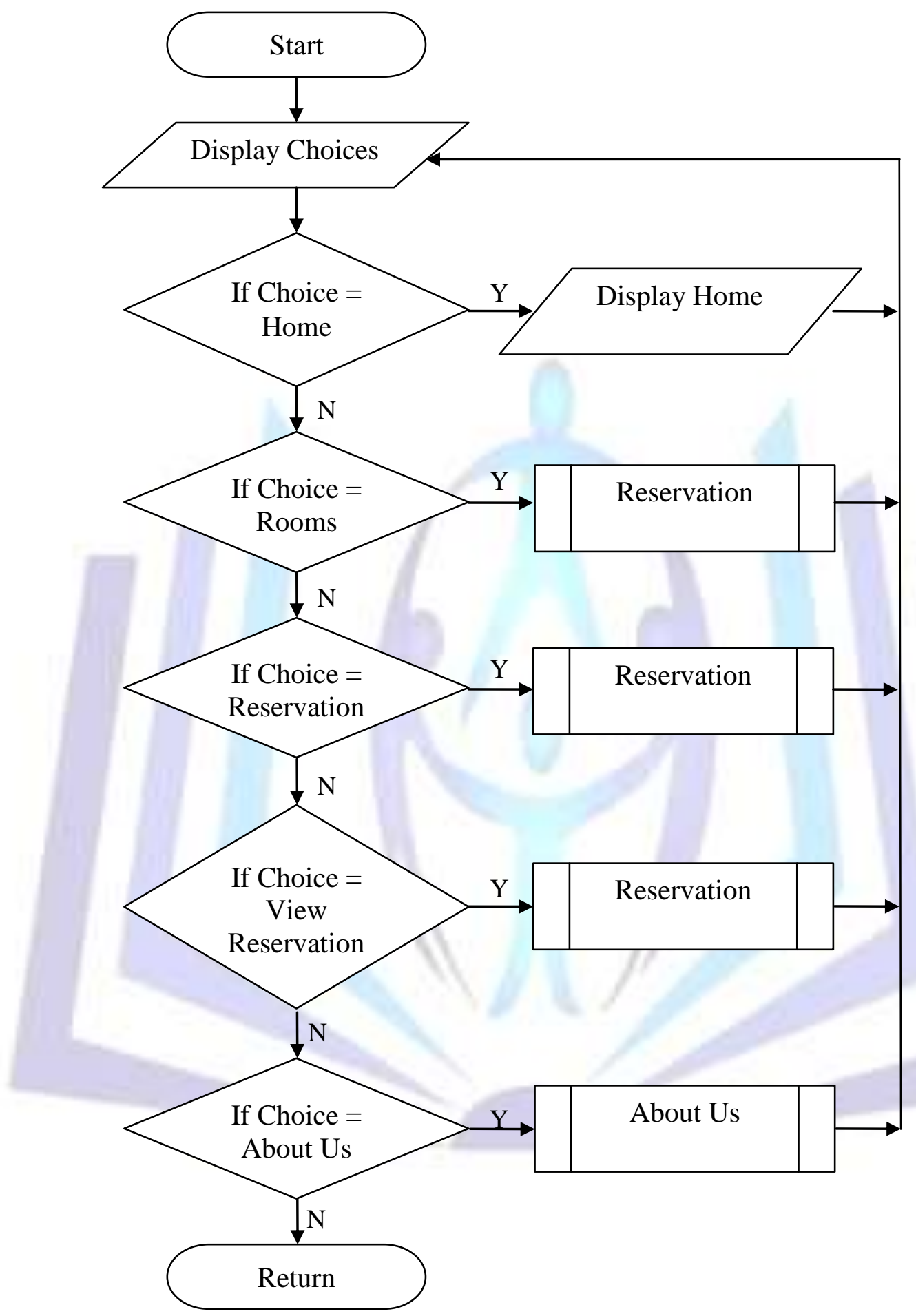

Figure 13. Student

The figure displays the Student account information which contains links like Home, Rooms, Reservation, View Reservation and About Us. The student account has the same interface as the administrator account, except the capability of adding, editing and deleting accounts. It also has the View Reservation button which is the record keeping tool to determine the clients who have checked in or checked out on the hotel. 


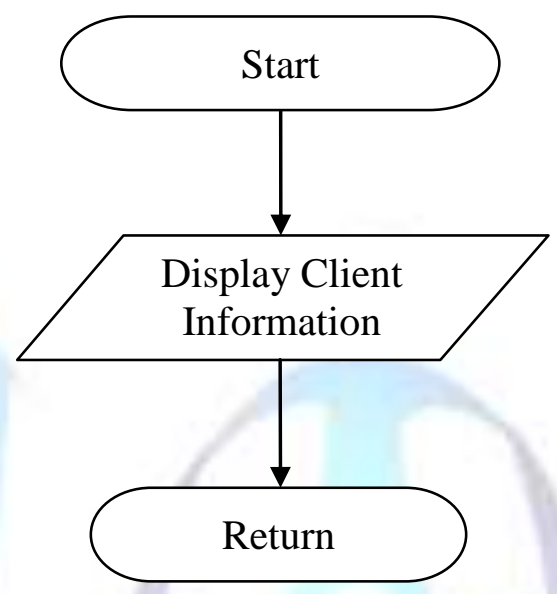

Figure 14. View Reservation (Student)

The figure shows the View Reservation Button under the student account of the Online Hotel Reservation System. This will allow the user to view the list of the reservations made. It also displays the date that the customer has checked in and how long the customer will stay. 


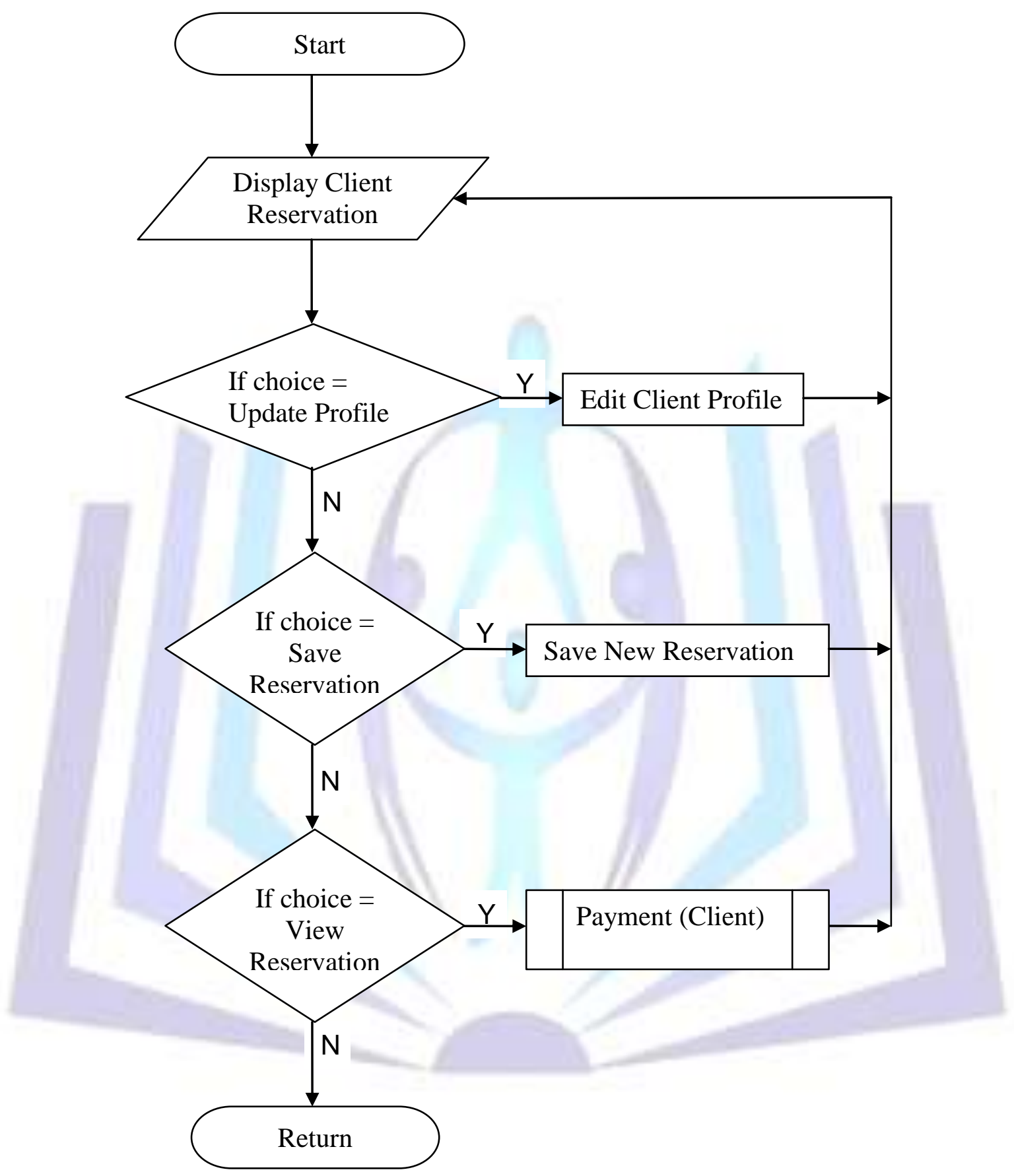

Figure 15. Reservation (Client)

This figure shows the page for the client that displays the reservations made, updating the profile or saving new reservation. The system also saves the information of the client so that when he makes a reservation for the second time he will no longer register again on the system. 


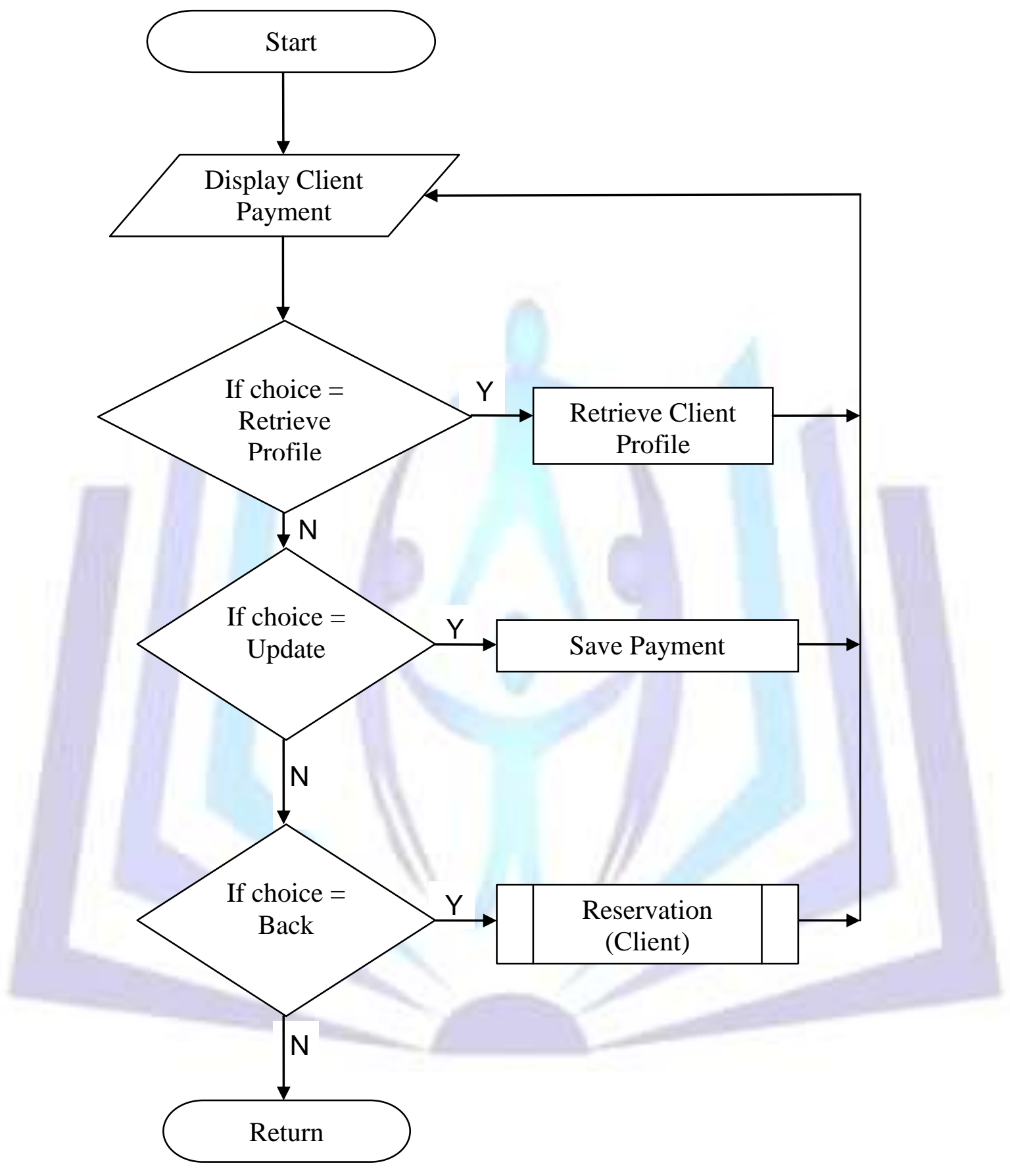

Figure 16. Payment (Client)

This figure shows what will be displayed when the client wishes to view the reservations made. The payment details will be shown and also an option for updating the payment. This is necessary in order to review the information made by the client before sending it on the system. 


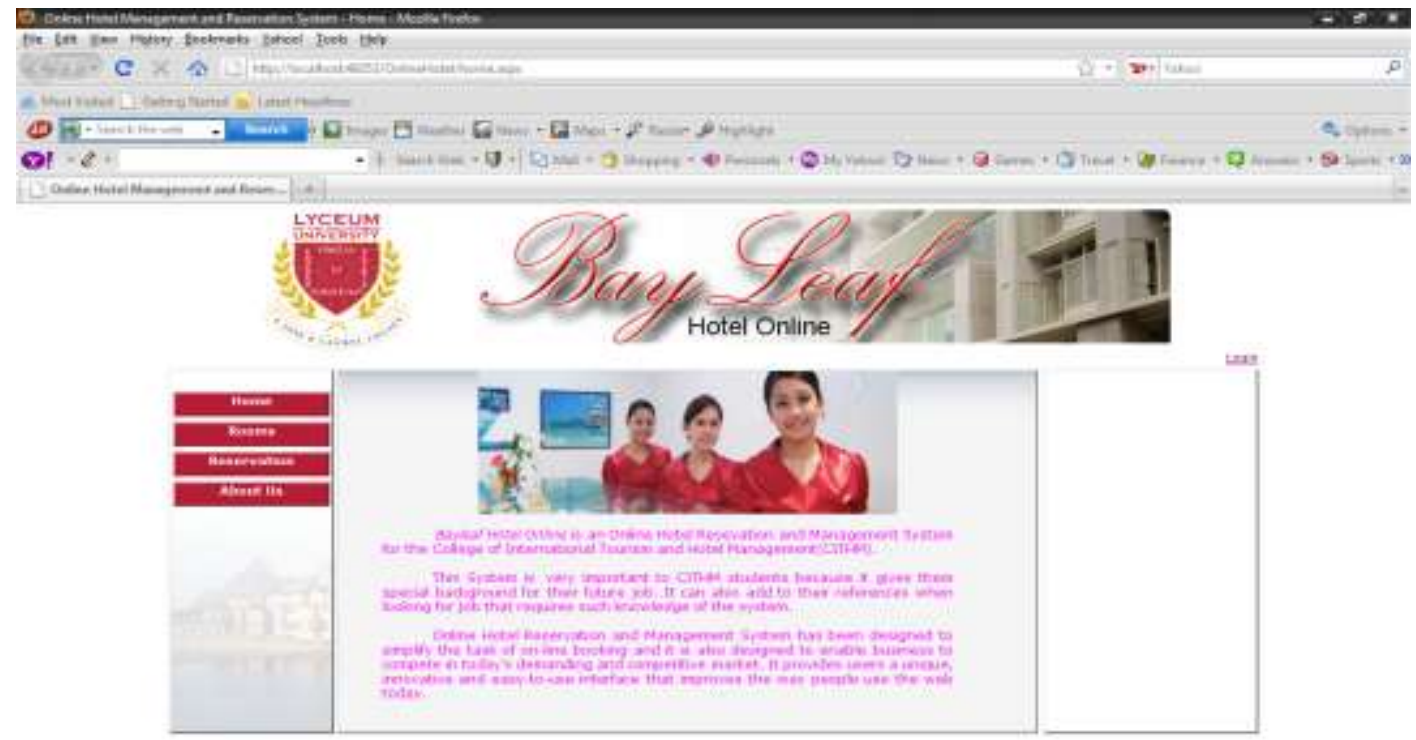

포

Figure 17. Home

The figure shows the Home Page of the Online Hotel Reservation System for CITHM. It contains the four major links- Home, Rooms, Reservations and About Us.

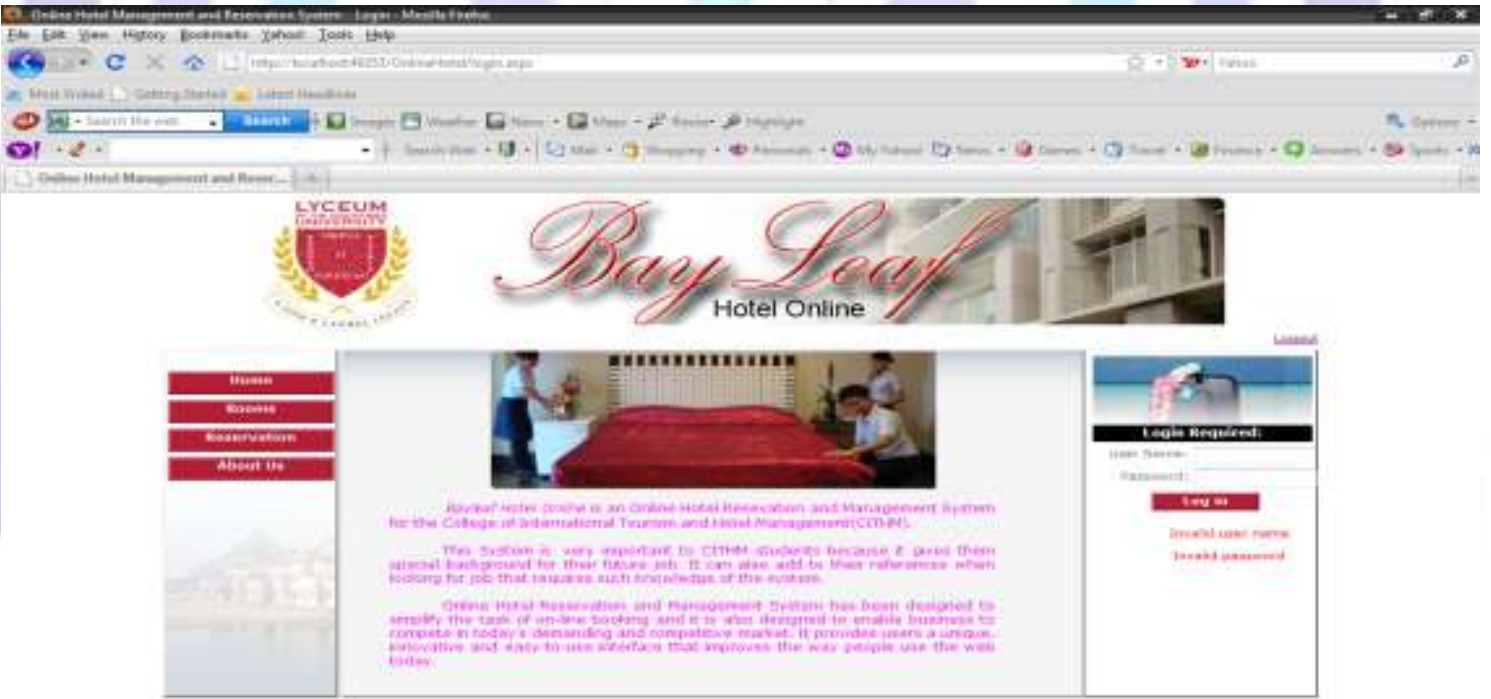

Figure 18. Login

Figure 18 shows the login page wherein the user will login as admin, student or client. 


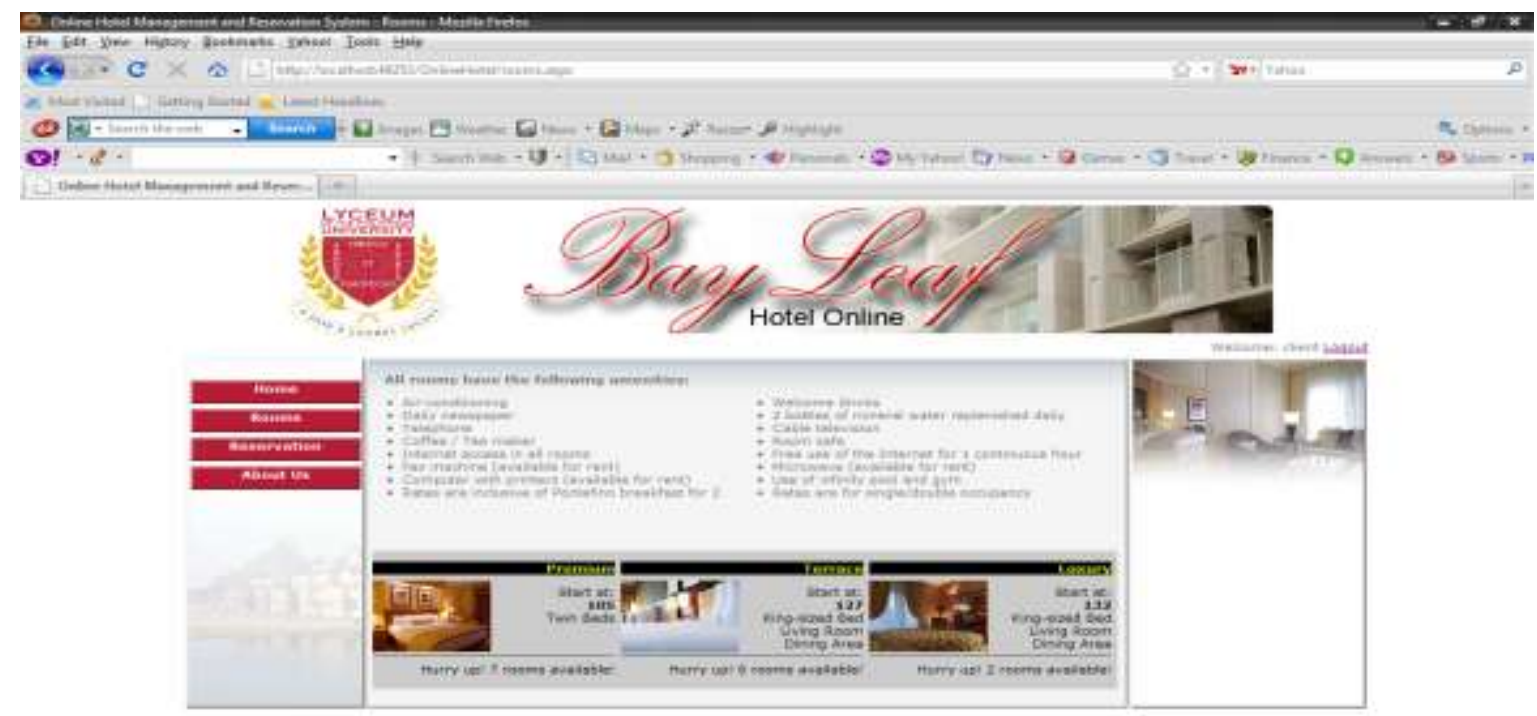

Figure 19. Rooms

The figure displays the types of rooms present in the hotel with the corresponding rate per hour and the amenities. The client can choose from Premium, Terrace or Luxury.

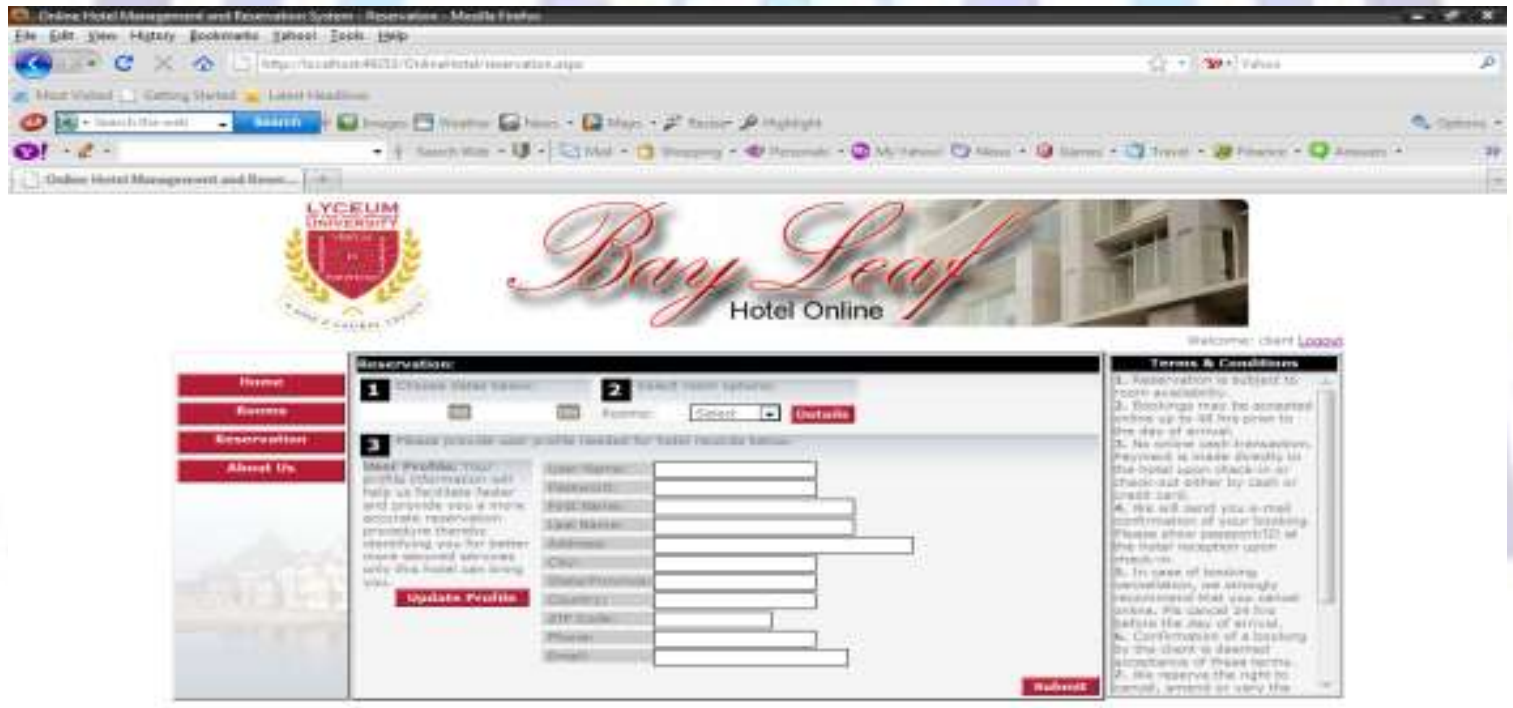

Figure 20. Reservation

The figure shows the reservation process once the user has logged in on the system. 


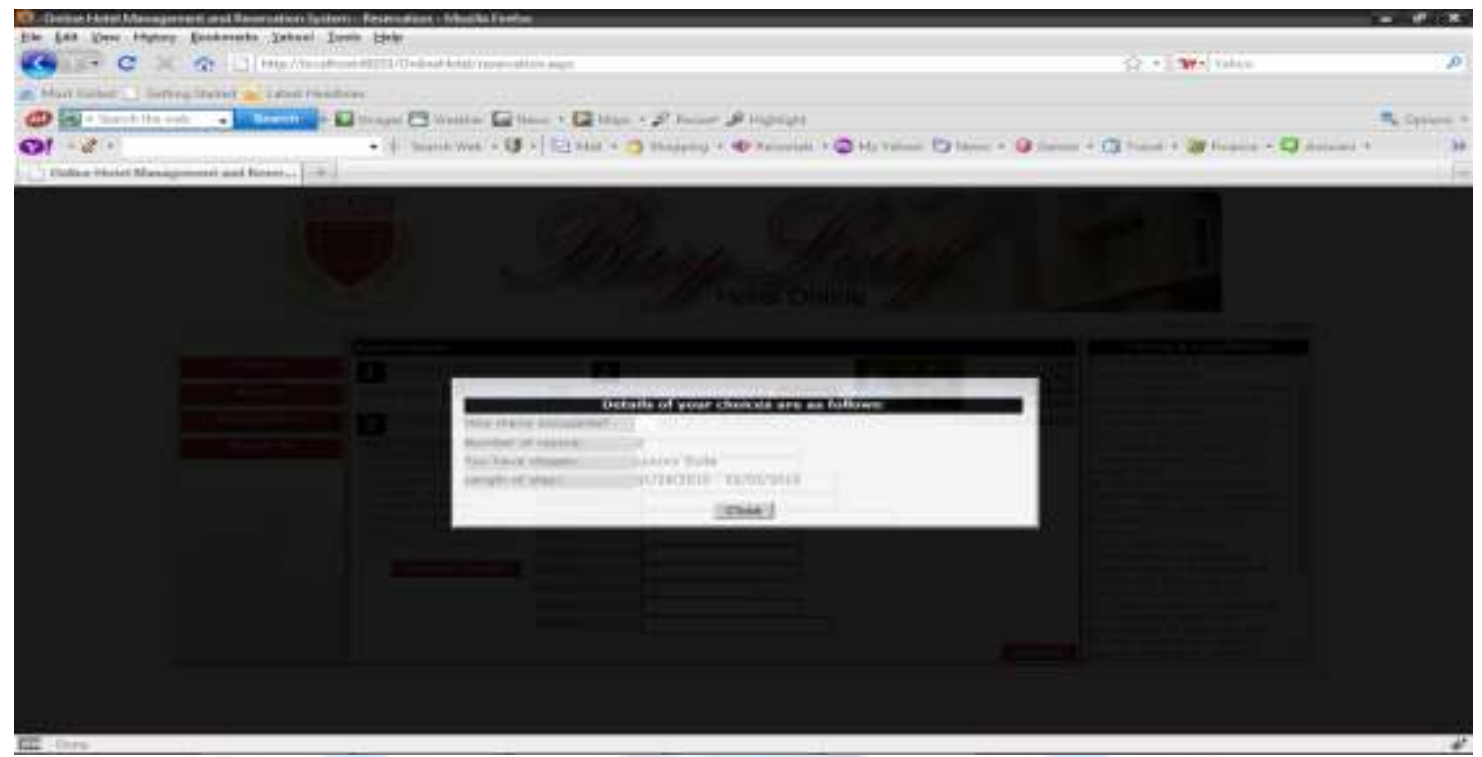

Figure 21. Details

Figure 21 shows the details of the reservation process wherein the client will choose the type of rooms, the number of rooms and occupants and the length of stay.

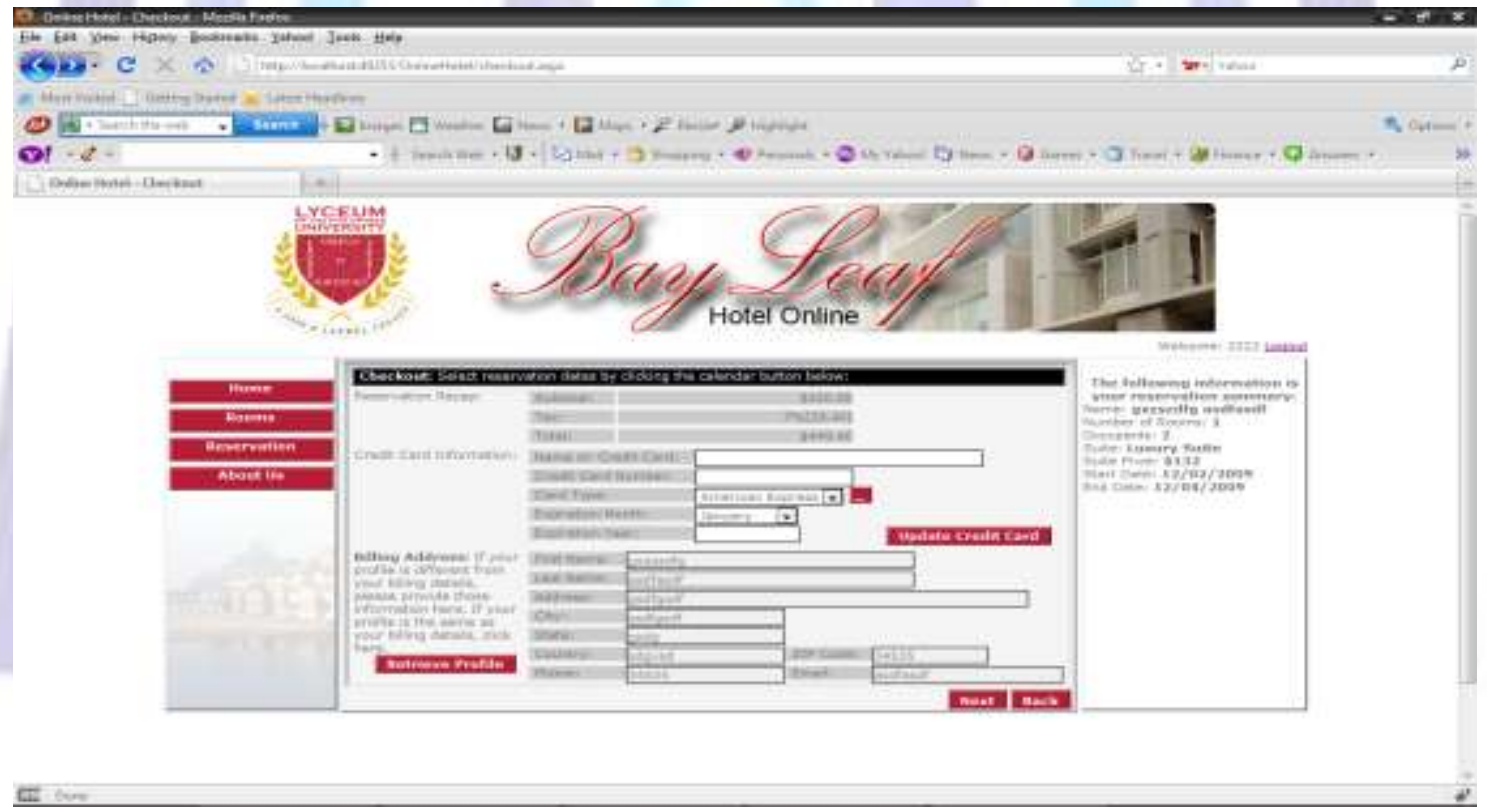

Figure 22. Payment

The figure shows the payment scheme of the hotel reservation system. This is needed for confirmation of the reservation. The client needs to pay $10 \%$ of the reservation as down payment. 

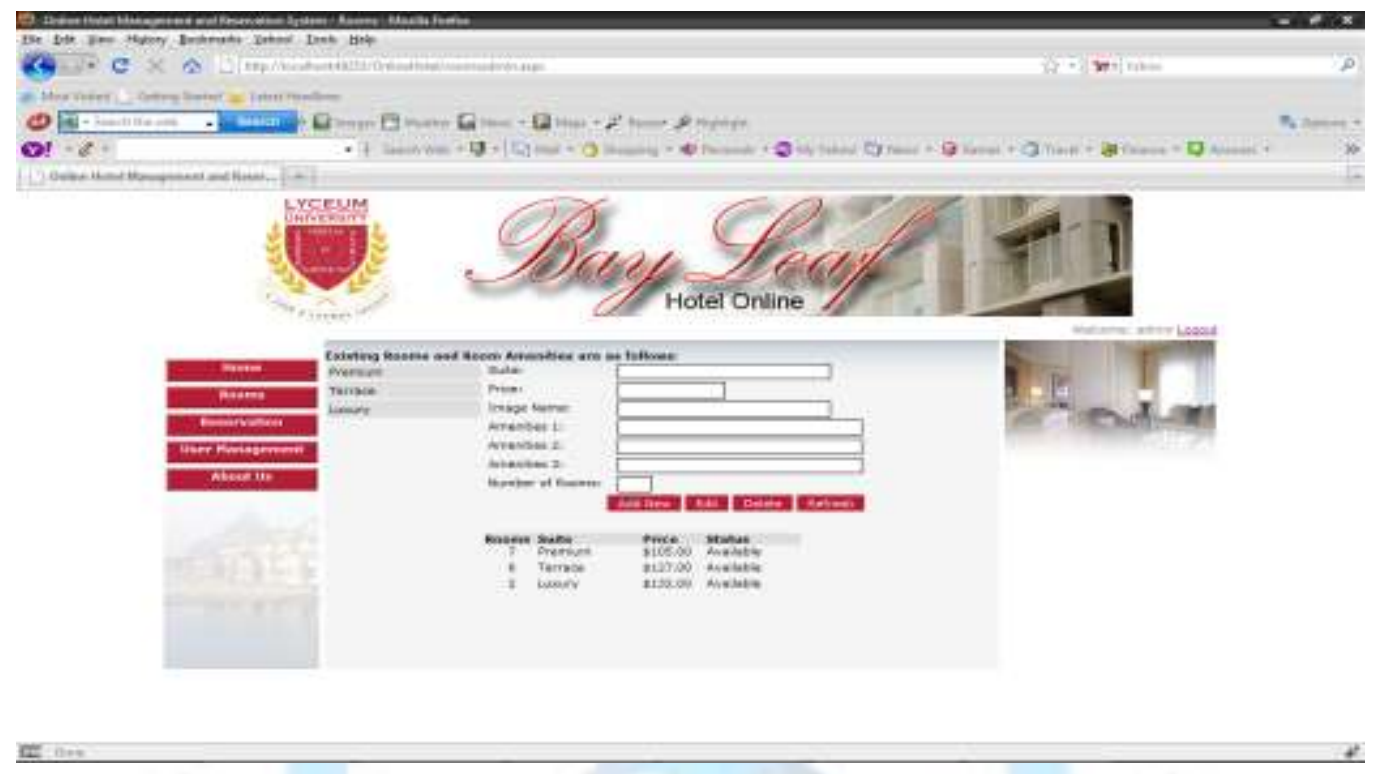

Figure 23. Rooms (Admin)

This page is for the administrator account. As an administrator, he has the control of the system. Under the Rooms link, the administrator has the capability of adding, updating or deleting rooms, room rates and amenities of the hotel.

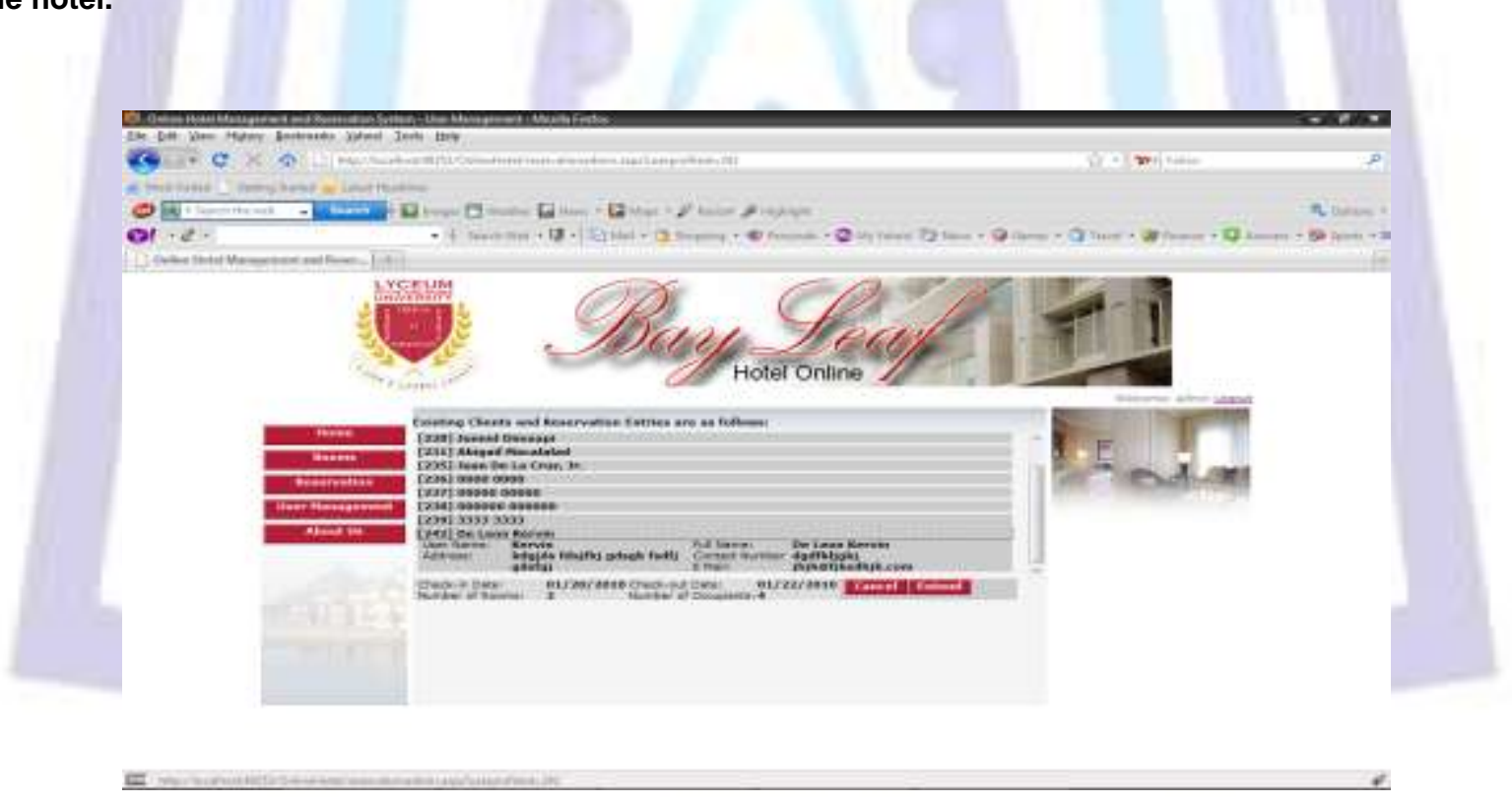

Figure 24. Reservation (Admin)

Figure 24 shows the reservation page for admin. Only the administrator can cancel or extend the reservation made by the client. 


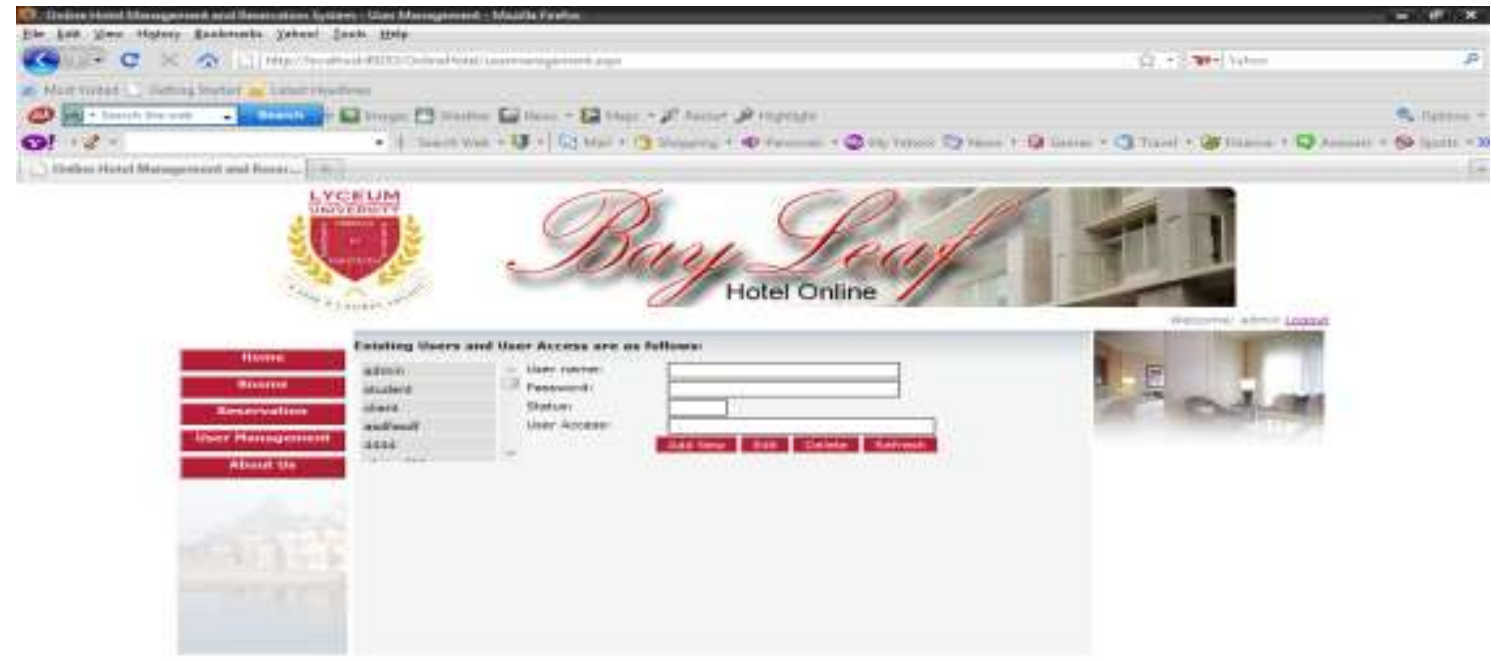

Figure 25. User Management

The figure shows the user management page under the administrator account. The admin can view the users who register on the system and he has the capability to add new accounts, and edit and delete the existing accounts.

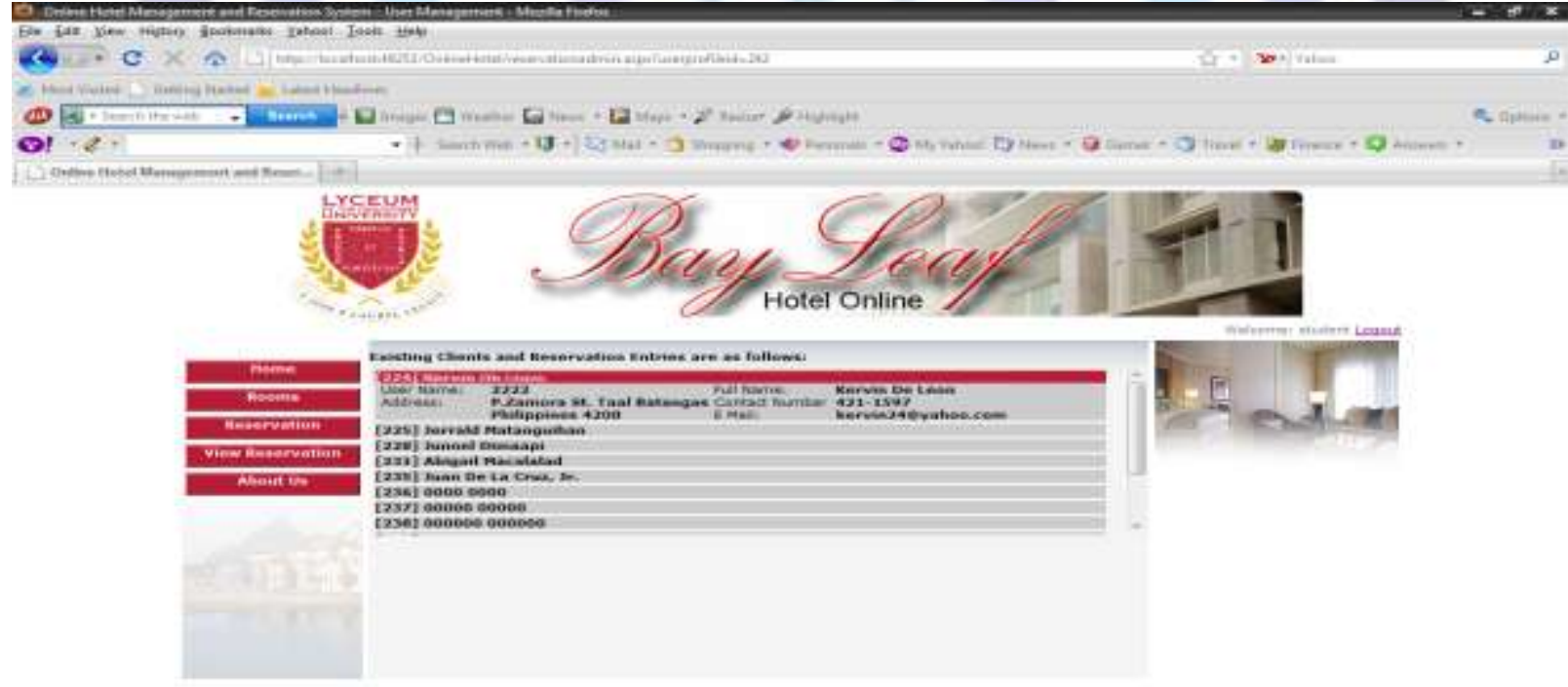

Figure 26. View Reservation (Student)

The figure shows the View Reservation link under the student account. It displays the reservation information made by the clients. 

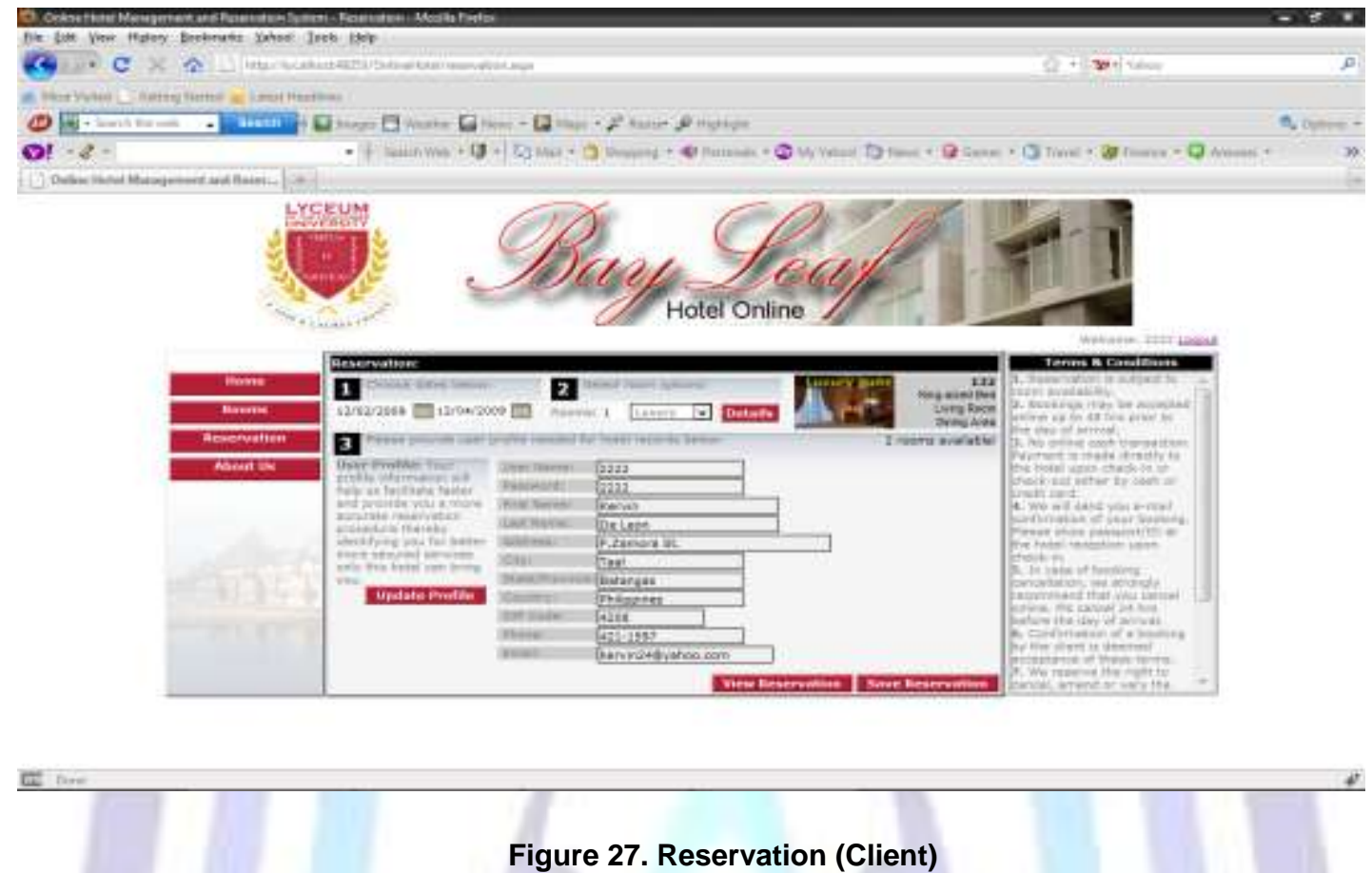

Figure 27 shows the reservation page of the client. The client may wish to check the details of the reservation before sending it to the system.

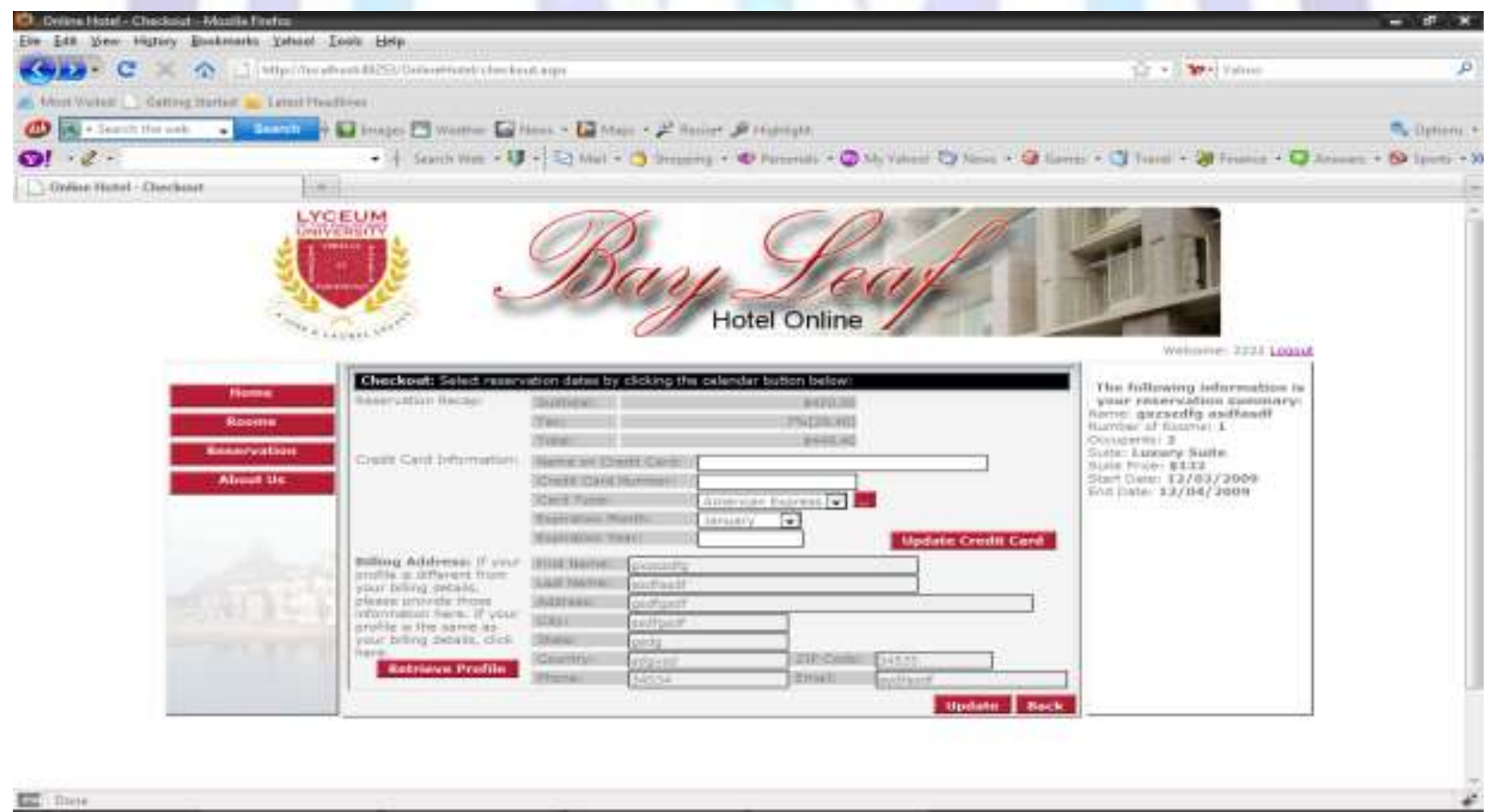

Figure 28. Payment (Client)

The figure displays the payment details made by the client. The client can also check the payment details before sending the reservation to the system. 


\section{DISCUSSIONS}

The main purpose of this study was to design and develop an online reservation system that will be used by the faculty members and students of College of International Hospitality Management for simulation purposes. With the system, students will be able to experience the real scenario for the jobs related to hotel reservation and management.

Online Hotel Reservation System for the College of International Hospitality Management serves as a tool for the faculty members to teach their students the basic operations of hotel reservation. It also serves as an aid for the students since the system will provide additional knowledge and skills on how to operate an online hotel reservation system which is the trend on most hotel businesses.

Online Hotel Reservation System for the College of International Hospitality Management serves as a tool to improve the services in the delivery of instruction since faculty members can access the system and they will no longer purchase a similar system for the students.

For security purposes, the system required a username and password assigned to each account. A system administrator monitored and supervised the creation of student and client accounts.

\section{CONCLUSIONS}

Based on the findings of the study, the following conclusions were drawn within the limitation and scope defined in the study.

- $\quad$ The online hotel reservation system was developed for the College of International Hospitality Management.

- The developed software presented features that helped the CITHM students in familiarizing with an online hotel reservation system.

- The developed software served as a tool for the instructors in teaching the basic operations of an online hotel reservation system to their students.

- The developed system also presents features and online security to protect privacy and financial information of clients.

\section{RECOMMENDATIONS}

After having evaluated the findings of the study, the following recommendations were hereby suggested:

- This system should be used by the CITHM students to give further knowledge about online reservation and hotel management.

- $\quad$ Future researchers and developers can add modules and additional features as this system is open for further improvements and developments because of the fast pacing changes in technology.

- A follow up study should be conducted to determine the usefulness and effectiveness of the developed system upon implementation.

\section{REFERENCES}

[1] Aldea et al. (2005) "Computerization of Hotel and Restaurant Management of Auzter's Plaza" Unpublished Thesis, Lyceum of the Philippines University

[2] Atienza et al (2004), "Automated Reservation and Billing System of Juan Carlo Caterer, Unpublished Thesis, Lyceum of the Philippines University

[3] Basco et. al (2007) "Webpage Development of Villa Carmelita Resort" Unpublished Thesis, Lyceum of the Philippines University.

[4] Business Travel World (July 2005). Online Hotel Reservation SystemRetrieved from ERIC database. (17689182)

[5] Culita et. al (2006) "Reservation System of Midland Pacific Hotel", Unpublished Thesis, Lyceum of the Philippines University

[6] Jiaqin Yang, Jan Flynn and Krista Anderson of Georgia College and State University (2005) E-Business Application in the Hospitality Industry: A Case StudyCommunications of the International Information Management Association, Volume 3 Issue 1

[7] Napier, H.A., Judd, P.J., Rivers, O.N., and Wagner, S. W. (2001), Create A Winning E-business, Thomson Learning, Boston, MA.

[8] Online Hotel Reservation Software. (n.d.). In dotcomtechno.com. Retrieved November, 2009 from http://www.dotcomtechno.com/ohrm.html

[9] Palmer, J. (1999). "Digital newspapers explore marketing on the Internet", Communications of the ACM, v42, p.3340. 
[10] Pringle, Stuart M. (1995) International Reservations Systems - Their Strategic and Operational Implications for the UK Hotel Industry. PhD thesis, Napier University. (http://researchrepository.napier.ac.uk/2785/

[11] Schneider, G.P. and Perry, J. T. (2001), Electronic Commerce, Thomson Learning, Boston, MA.

[12] Web Development Methodology. (n.d.). In Web Transition.com. Retrieved November, 2009 from http://www.webtransitions.com/articles/web-development-methodlogy.asp

[13] Web Development Methodology. (n.d.). In Web Transition.com. Retrieved November, 2009 from http://www.webtransitions.com/articles/web-development-methodlogy.asp

\section{Author' biography}

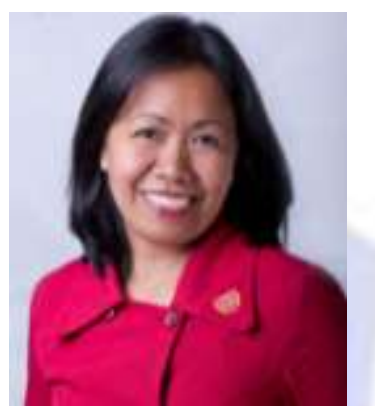

GLENDA ACORDA DELIZO is working as Information technology instructor at Lyceum of the Philippines University under the College of Computer Studies. Forfive years, she has been handling professional subjects like web development, computer applications, computer programming and multimedia technologies. She finished her BS in Computer Science at Batangas State University in 1999 and she is currently finishing her Master of Science in Information Technology at the same university. Her focused research area includes systems development and multimedia systems. She is also a member of Philippine Society of Information Technology Educators and Computer Science Teachers Association (CSTA).

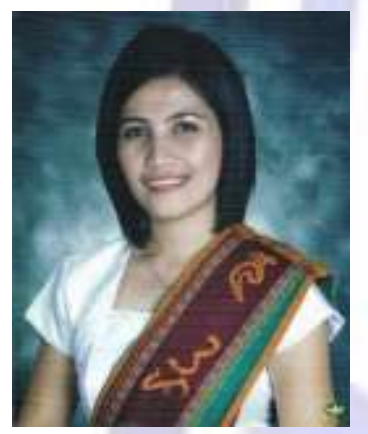

MISCHELLE ASI ESGUERRA is working as college instructor at Lyceum of the Philippines University under the College of Computer Studies and been teaching for 5 years handling professional subjects like computer applications, programming and project management. She received her Master of Information Systems (MIS) degree from University of the Philippines- Open University in 2011 and her BS in Information Communications Technology from LPU in 2007. Her focused research area includes systems development, management information system and mobile application development. She's also a member of Philippine e-Learning Society (PeLS) and Computer Science Teachers Association (CSTA). Currently, she's the department chair for BS Information Technology. 